\title{
La comunidad monástica de Santa María de Nájera durante la Edad Media
}

\author{
The Monastic Community of Santa María de Nájera \\ during the Middle Ages
}

\author{
Margarita Cantera Montenegro \\ Universidad Complutense. Madrid \\ mcantera@ucm.es
}

\section{RESUMEN}

La incorporación del monasterio de Santa María de Nájera a Cluny supuso la organización interna del cenobio de acuerdo con las normas propias de la Orden. En este trabajo se analizan los diversos oficios monásticos durante los siglos medievales, destacando los hechos más representativos de este período, así como la importancia de la comunidad monástica y su formación intelectual; de forma especial se estudia, en cuanto es posible, la procedencia geográfica de los monjes, considerando la fuerte presencia de franceses en los primeros años, y la permanencia de éstos en el cargo de prior durante mucho tiempo.

Palabras clave: Historia de la Iglesia, Monacato medieval, Orden de Cluny en Castilla, Cultura monástica. Nájera.

\begin{abstract}
The inclusion of the monastery of Santa María de Nájera in Cluny involved its internal organization according to the rules of that monastic Order. In this work, different monastic positions during the medieval ages have been analyzed, stressing the most representative events of the period, as well as the importance of the monastic community and its intellectual training; specifically, the geographical origin of the monks has also been studied to the extent possible, considering the notable French presence in the first years and for a long time after that in the post of the prior.
\end{abstract}

Key words: Church History, Medieval Monasticism, Cluniac Order in Castile, Monastic culture, Nájera

Sumario: 1. Prior mayor. 2. Abad. 3. Prior claustral. 4. Camarero o tesorero. 5. Sacristán. 6. Limosnero. 7. Enfermero. 8. Mayordomo o cillerero. 9. Refitolero. 10. Obrero o mayordomo de la obra. 11. Sochantre o armarius o cantor. 12. Clavero y portero. 13. El convento y el capítulo conventual. 14. Número de monjes. 15. Procedencia geográfica de los monjes de Santa María de Nájera. 16. Nivel cultural de los monjes de Santa María de Nájera. 17. Conclusiones. 
El cenobio de Santa María de Nájera fue fundado en 1052 como cabildo canonical por el rey navarro García III: pero poco después, en 1079, se integró en la Orden de Cluny por decisión del monarca castellano Alfonso VI, hecho jurídico que ratificó Alfonso VIII en $1175^{1}$.

La unión a Cluny supuso la sumisión total a la abadía francesa, cabecera de una Orden centralizada, vinculada directamente a Roma y exenta de la jurisdicción diocesana. En el caso concreto del cenobio najerense conllevó su transformación en priorato y la aceptación plena de las costumbres cluniacenses, la obediencia al abad y el cumplimiento de todos sus mandatos disciplinarios. Por ello, el monasterio se integró en la organización provincial de la Orden, en concreto en la provincia de España, que comprendía todo el territorio situado al sur de los Pirineos ${ }^{2}$. En cada provincia, el camarero o camerario representaba al abad de Cluny.

La unidad de la Orden se aseguró en buena medida por medio de las visitas y los Capítulos Generales. También a través de unas y de otros se hacía presente en todas las casas la autoridad del abad.

Integrado en la organización cluniacense, el monasterio de Nájera estructuró su comunidad de acuerdo con las normas de vida de la Orden. La autoridad suprema del cenobio descansaba en manos de un prior mayor, siempre vinculado al abad de la casa madre, que era quien lo designaba. Y así sucedió hasta que en 1486, empezando el proceso de separación de la Orden, los monjes de Nájera, al fallecer el prior Gonzalo de Cabredo, eligieron para el cargo al que en ese momento era enfermero y tesorero, Pablo Martínez de Uruñuela, sin esperar la decisión del abad, como era preceptivo ${ }^{3}$.

Los demás oficios del monasterio eran designados y revocados por el prior, según declaró quien ejercía ese cargo en 1385, al afirmar que dichos oficios sólo eran administraciones que se davan por el dicho prior por la forma que le plasía et a quien era su voluntad, et las tirava e mudava quando quería, et las dava a otras personas que él entendía que las administrarían mejor; et que así era acostumbrado en el dicho monesterio en los tienpos pasados fasta aqui $i^{4}$. Este alegato era la respuesta a la demanda presentada por el colector del papa en la Corona de Castilla, Guillén de Mondrevilla, respecto al pago de la media anata que, de ser oficios perpetuos y no revocables, debería entregar el monasterio a la Cámara apostólica. Finalmente, Martín Asteti, colector del papa en la diócesis de Calahorra-La Calzada, ratificó en 1412 la

${ }^{1}$ Margarita CANTERA MONTENEGRO, Santa María la Real de Nájera. Siglos XI-XIV [en adelante Santa María la Real de Nájera], Madrid, 1987, II, 10, 22 y 75; y Colección documental de Santa María de Nájera. Tomo I (siglos X-XIV) [en adelante Colección documental], San Sebastián, 1991, docs. 10, 22 y 75.

${ }^{2}$ Aunque todo el monacato español del momento está impregnado del espíritu cluniacense, son muy pocos los monasterios principales que dependían jurídicamente de Cluny y son éstos los que forman la provincia española; entre ellos está el de Nájera.

${ }^{3}$ Estaba establecido que el prior no podía ser designado por los monjes de su monasterio; incluso se amenazaba con la excomunión al que aceptase ser designado por ese medio (Guy DE VALOUS, Le monachisme clunisien des origes au $X V^{E}$ siècle, $2^{\circ}$ ed., París, 1970, I, pp. 187). El temor de los monjes a actuaciones contra ellos, quizás por este motivo, se ve en la solicitud de amparo regio que realizó el prior electo y a la que respondieron los Reyes Católicos concediendo carta de amparo tres días antes de que el papa Inocencio VIII confirmara la elección hecha (Margarita CANTERA MONTENEGRO, Colección documental de Santa María de Nájera, siglo XV. Regesta documental [en adelante Regesta documental ], Logroño, 2011, $\mathrm{n}^{\mathrm{o}} 265$ y 266 respectivamente).

${ }^{4}$ M. CANTERA, Santa Maria la Real de Nájera, III, doc. 366. 
postura del prior, reconociendo el carácter revocable y no perpetuo de los oficios de prior claustral, sacristán, enfermero, limosnero, cillerero, cantor y todos los oficiales de Santa María de Nájera 5 .

A pesar de esa independencia de la que debía gozar el monasterio para la designación de los diversos cargos, a excepción del prior mayor, algunos abades de Cluny intentaron por diversos medios ejercer un control en este asunto; y, para ello, lo primero era exigir una información exacta y completa de los nombramientos realizados. Como muestra patente de estas intervenciones, el abad Odón ordenó en 1448 que cuando se produjese alguna novedad en los oficios del priorato se hiciese volver a su estado originario y acostumbrado; y exigía que se le comunicara toda actuación que se realizara en este sentido. Es fácil suponer que se refiere a una intervención directa del abad en la vida del monasterio. Sin embargo, tras la celebración de Capítulo General, y atendiendo a la súplica del prior Pedro Martínez de Santa Coloma, el abad revocó la orden anterior y permitió disponer libremente de los oficios claustrales, como solía hacerse en la Orden de Cluny ${ }^{6}$.

De todas formas, y a pesar de esta declaración, dicho abad Odón mantuvo su ánimo intervencionista y, dos meses después, nombró enfermero del cenobio najerense a Pedro García de la Puente, declarando que el nombramiento correspondía al abad siguiendo la antigua costumbre ${ }^{7}$.

En este trabajo voy a examinar los diversos oficios del monasterio, señalando sus funciones y algunos de los hechos más destacados, aunque sin entrar en detalles sobre las personas que los ejercieron, para recoger al final la relación de los oficiales con las fechas en que consta el desempeño de su función.

\section{PRIOR MAYOR}

El prior cluniacense es un representante del abad de Cluny, designado por él y al que debe juramento de fidelidad. Tiene en su monasterio los mismos poderes que el abad de la Orden; y debe responder ante él y ante el Capítulo General del buen estado espiritual y moral de los monjes, del cumplimiento de los deberes de limosna y hospitalidad y de la celebración regular de la liturgia ${ }^{8}$.

El cargo de prior es vitalicio, al menos a partir del siglo XIII; y, aunque la designación fuese realizada por el abad de Cluny, corresponde al papa la provisión del cargo, según consta hizo Calixto II a favor de Gonzalo de Cabredo en $1456^{9}$.

Sin embargo, algunos priores ocuparon el puesto en períodos alternos, dejándolo para asumir otro priorato o por motivos que no se expresan. Esta discontinuidad se

${ }^{5}$ M. CANTERA, Regesta documental, $\mathrm{n}^{\circ} 69$.

${ }^{6}$ M. CANTERA, Regesta documental, $\mathrm{n}^{\circ} 152$. El texto dice así: Nuper vero vobis exibita pro parte vestra humilis supplicatio continebat ut de eisdem officiis prioratus nostri de Nagera franche et libere disponere valeatis prout et quemadmodum poteratis et prout est solitum in ordine nostro Cluniacensem ante huiusmodi novitatem.

${ }^{7}$ M. CANTERA, Regesta documental, $\mathrm{n}^{\circ}$ 153: De iure nostro et antiqua consuetudine.

${ }^{8}$ G. VALOUS, Le monachisme I, pp. 187-188 y 198-204.

${ }^{9}$ M. CANTERA, Regesta documental, $\mathrm{n}^{\mathrm{o}} 176$. 
produjo con Jimeno, si efectivamente tuvo dos etapas de mandato: una primera, documentada entre 1197 y 1201; y, separada de la anterior por el priorato de Gerardo, una segunda hacia 1207, según afirma Argaiz ${ }^{10}$, aunque no hay otros testimonios de ello. En 1220, y tras los prioratos de Alano y Guigón, encontramos de nuevo un prior de nombre Jimeno; dado que el intervalo cronológico no es muy grande (20 años como mucho), podría tratarse de la misma persona. Este dejar y retomar el cargo por parte de Jimeno quizás se debió al descontento de los monjes con su actuación, pues la noticia más destacada que conservamos de él es el informe que redactó en 1201 para explicar su gestión económica. Reglero de la Fuente piensa que pudo ser removido del cargo ante la acusación de haber dilapidado los bienes del monasterio, lo que explicaría su autojustificación. Pero también es posible que su proximidad a Diego López de Haro hiciese recomendable su relevo durante el exilio del conde de la corte castellana, entre 1201 y 1206, para evitar que su persona y simpatía hacia la causa del noble provocasen también la desgracia del monasterio ${ }^{11}$.

Se suele designar para el priorato a un sacerdote; y sus funciones son: dirigir la vida del monasterio y vigilar a los monjes, presidir el capítulo conventual y dar instrucciones a los distintos oficiales para la organización diaria del cenobio. En el aspecto material, es el encargado de la administración y explotación de los bienes muebles e inmuebles del priorato; $y$ es el representante del cenobio ante el mundo exterior en los actos jurídicos (donaciones, compraventas, intercambios...). Una vez designado, el prior recibía la promesa de obediencia por parte de los monjes y de los clérigos de la ciudad vinculados al cenobio, destacando los de la capilla de Santa Cruz, establecida dentro del monasterio. A continuación tomaba posesión de los lugares pertenecientes al cenobio y recibía el juramento de vasallaje de sus vecinos ${ }^{12}$.

Pese a sus obligaciones, y mientras éstas no se lo hiciesen imposible, el prior debía seguir participando en la vida común del monasterio; es decir, celebrar la misa conventual en las fiestas señaladas, así como comer en el refectorio, dormir en el dormitorio común, asistir al coro y al capítulo conventual. Sin embargo, es dudoso que, al menos en el siglo XV, se cumpliese la obligación de residir en las estancias comunes, ya que el prior disponía de las suyas propias, los palacios priorales. Así consta por la donación que en 1407 hizo el convento al prior Rodrigo de unas casas que el cenobio poseía junto al monasterio, con objeto de ensanchar vuestra casa, que es muy estrecha ${ }^{13}$. Asimismo, en 1479 se celebró el capítulo conventual en dichos palacios, que serían denominados palacios abaciales a fines del siglo $\mathrm{XV}^{14}$.

Los amplios poderes del prior mayor tenían ciertas limitaciones, que se manifiestan en el preceptivo consejo que debía pedir al capítulo conventual para resolver los

${ }^{10}$ Gregorio de ARGAIZ, La Soledad laureada por San Benito y sus hijos en las iglesias de España, y Teatro monástico de la provincia Tarraconense, II, Madrid, 1675, fol. 377 r.

11 Carlos M. REGLERO DE LA FUENTE, Cluny en España. Los prioratos de la provincia y sus sedes sociales (1073-ca. 1270) [en adelante Cluny en España], León, 2008, pp. 497-498.

12 M. CANTERA, Regesta documental, $\mathrm{n}^{\circ} 275$ y 277. El primer documento es la promesa de obediencia realizada por los monjes al prior Pablo Martínez de Uruñuela; y el segundo es la recepción de las dependencias, ambos textos datados en 1487 .

13 M. CANTERA, Regesta documental, nº 38. El monasterio imponía como condición para esta donación que se hiciesen bodegas grandes en dichas casas para guardar el vino del convento.

14 M. CANTERA, Regesta documental, n² 247, 440, 477, 478 y 542, respectivamente. 
asuntos más importantes, la información que tenía que ofrecer a dicho capítulo dos veces al año respecto al gobierno material del cenobio y la obligación de rendir cuentas anualmente al abad de Cluny. Además, para controlar mejor la administración económica, el Capítulo General de 1300 decretó que el camarero provincial debía realizar, en presencia de los monjes, un inventario de los bienes del priorato cada vez que fuese designado una nueva persona para el cargo.

En los primeros años de su historia, los priores de Santa María de Nájera eran monjes franceses $y$, seguramente, personas de plena confianza del abad que los designaba, garantizando así, al igual que en otros prioratos distantes geográficamente de Cluny, la vinculación a la casa madre. El nombre de dichos priores refleja con claridad este origen francés.

El primer prior cluniacense de la comunidad najerense fue Marcelino ${ }^{15}$, designado por el abad de Cluny san Hugo, quien también nombró a su sucesor, Raimundo. El abad Poncio nombró dos nuevos priores: Efredo y Pedro Bellino.

Pedro el Venerable enviará después a Esteban (I), de quien el cronista de la Orden benedictina fray Antonio de Yepes destaca su religiosidad y buena observancia; lo enmarca entre 1135 y $1144^{16}$, aunque las referencias documentales de su persona se interrumpen en 1140. Dejó el priorato de Nájera al ser designado obispo de Osma ${ }^{17}$; y es posible que hubiera sido abad de Sahagún ${ }^{18}$.

En los años centrales del siglo XIII dirigieron el monasterio najerense los priores Bernardo ${ }^{19}$; Juan, posiblemente sacristán del cenobio unos años antes ${ }^{20}$; Bosón, que también era camarero de la Orden en España ${ }^{21}$; y Arnulfo, que recibió importantes privilegios de los monarcas Alfonso VII y Sancho III de Castilla.

$\mathrm{Su}$ sucesor fue Raimundo, designado por el abad Pedro Mauricio y que también contó con la protección de los reyes de Castilla, así como de la poderosa familia de los Haro. Pero, acusado de simonía, fue desterrado por Alfonso VIII en 1169 ó 1170, al tiempo que le prohibía toda administración de bienes eclesiásticos. La acusación parece responder a un hecho real, ya que el papa Alejandro III ordenó su reclusión en el claustro de Cluny por haber falsificado, previo pago de dinero (es decir, cayendo además en simonía), unas cartas que se atribuían al legado pontificio y por las cuales

${ }^{15}$ Antes que él rigió la comunidad de Nájera, entonces de canónigos, el prepósito Galindo.

${ }^{16}$ Coronica general de la Orden de San Benito, patriarca de religiosos, (Valladolid, 1609-21) Madrid, 1960, III, p. 118.

17 Ildefonso RODRÍGUEZ DE LAMA, Colección diplomática medieval de La Rioja (923-1225), Logroño, 1979, I, p. 80. El Diccionario de Historia Eclesiástica de España, III, Madrid, 1973, p. 1488, señala el año 1141 como inicio de su pontificado, fecha que se ajusta mejor a la ausencia de noticias suyas al frente del cenobio desde 1140 .

${ }^{18}$ C. REGLERO DE LA FUENTE, Cluny en España, pp. 212-214. De ser el mismo, en ambos monasterios contó con un notable apoyo de Alfonso VIII.

${ }^{19}$ Reglero de la Fuente (Cluny en España, p. 501) señala que en 1140 figura un Bernardo como prior de Carrión y posteriormente de Dueñas, en 1145, aunque dada la frecuencia de este nombre en la onomástica francesa no es posible afirmar que se trate del mismo.

${ }^{20}$ Así lo afirma Gregorio de ARGAIZ, La Soledad laureada, Madrid, 1675, II, fol. 373.

${ }^{21}$ Este hecho refleja la importancia del cenobio najerense dentro de la Orden, pues este cargo se vinculó de forma tradicional a este prior o al de Sahagún. 
era designado prior de San Millán de la Cogolla ${ }^{22}$. El destierro del prior Raimundo fue aceptado por el abad de Cluny, temeroso de la amenaza regia de confiscación de los bienes de todos los que se opusieran a la medida. De ese modo, para cubrir el cargo designó a Humberto en 1170, que fue al tiempo camarero y vicario general de la Orden para España; anteriormente había sido prior de Dueñas, y lo volvería a ser tras su etapa en Nájera; también ocupó el priorato de San Zoilo de Carrión desde 1169, simultáneamente con el de Santa María de Nájera ${ }^{23}$.

Arcado (Archadus), que había sido prior de San Román de Entrepeñas ${ }^{24}$, Hugo, Guido, Haimón ${ }^{25}$ y Duranio o Durando completan la lista de priores del siglo XII y también reflejan en su nombre el origen francés.

A caballo entre los siglos XII y XIII rige el cenobio Jimeno, del que ya he hablado, así como del informe económico que elaboró para justificar su gestión económica; en él afirma que encontró el monasterio en estado ruinoso, tanto por la mala administración de su predecesor Durando, como por los pleitos en que se veía envuelto el cenobio, especialmente el que sostenía con el obispo calagurritano. Como defensa de su labor, Jimeno enumeraba las adquisiciones que realizó durante su mandato y cómo había dejado el monasterio en situación muy distinta a la que tenía cuando asumió el cargo ${ }^{26}$.

Sus sucesores siguen reflejando el origen francés en sus nombres: Gerardo, nombrado por el abad Guillermo II; Alano; y Guigón o Guido. Éste hace explícita su extranjería alegando la dificultad que ello le supuso para encontrar abogados en el pleito que el cenobio mantenía con el obispo de Calahorra, quia est alienigena et extraneus et ignotus in partibus istis ${ }^{27}$.

Con un nuevo prior de nombre Jimeno, que podría tratarse del de principio de siglo, y su sucesor Juan, observamos que alternan priores de nombre franco, cada vez menos numerosos, con los hispanos. Este prior Juan recibió la sentencia condenatoria para el monasterio en el pleito con el obispo de Calahorra; pero no sólo la rechazó, sino que se opuso por las armas a la entrega de la iglesia, actitud en la que recibió el respaldo del rey de Castilla ${ }^{28}$.

Tras Juan ${ }^{29}$, ocupan el cargo Nicolás, Martín Pérez, que había sido sacristán del cenobio los años anteriores, y Guido. Gonzalo Pérez, nombrado por el abad Ibón, está

${ }^{22}$ M. CANTERA, Santa María la Real de Nájera, II, docs. 73 y 72; y Colección documental, docs. 73 y 72 respectivamente. C. Reglero de la Fuente (Cluny en España, pp. 216-218) señala que este asunto debe inscribirse en las luchas por el dominio de La Rioja y el enfrentamiento entre el papa Alejandro III y la Orden de Cluny.

${ }^{23}$ C. REGLERO DE LA FUENTE, Cluny en España, p. 218.

${ }^{24}$ C. REGLERO DE LA FUENTE, Cluny en España, p. 501.

${ }^{25}$ I. Rodríguez de Lama (Colección documental, III, p. 49, nota 1) se pregunta si este prior Haimón no será en realidad el anterior prior, Guido.

${ }^{26}$ Alexandre BRUEL y Auguste BERNARD, Recueil des chartres de l'abbaye de Cluny, París, 18761903, V, núm. 4403. Argaiz habla de un prior Jimeno hacia 1207, pero no hay constancia documental de él ( $L a$ Soledad laureada, II, fol. 377 r.).

${ }^{27}$ M. CANTERA, Santa María la Real de Nájera, II, doc. 132; C. REGLERO DE LA FUENTE, Cluny en España, p. 504.

${ }^{28}$ I. RODRÍGUEZ DE LAMA, Colección diplomática, III, doc. 481.

${ }^{29}$ Para Reglero de la Fuente (Cluny en España, p. 502), se trata de Juan de Carrión, prior de este cenobio entre 1219 y 1226 ó 1227, simultaneándolo unos años con Santa María de Nájera; y luego también lo fue de Villafranca. Fue prior de San Román entre 1245 y 1252; y de Dueñas entre 1254 y 1259. 
documentado en los años centrales del siglo XIII y anteriormente había sido prior de San Román de Entrepeñas y de Dueñas, mostrando un claro ascenso de categoría y riqueza de monasterios; simultaneó los prioratos de Dueñas y de Nájera, hasta que el Capítulo General de 1259 lo prohibió por estar muy alejados entre sí, de forma que no podía atenderlos convenientemente ${ }^{30}$. Su sucesor, Esteban, fue artífice de un acuerdo con su convento para resarcir las deudas que los priores anteriores habían contraído con la comunidad ${ }^{31}$.

Con Jofre o Godofre, designado por el abad Ibón I cuando era de edad avanzada, volvemos a encontrar una mayor presencia de nombres franceses, aunque alternando con los hispanos. Juan de Vargas fue camarero y vicario general de Cluny en España, al tiempo que prior najerense; y obtuvo de los monarcas Alfonso X de Castilla y Enrique II de Navarra la confirmación de diversos privilegios.

Tras su sucesor, Pedro Sánchez, predominan los nombres franceses: Yvo de Mont, Guillén de Busuel y Guillén de Monladún. Todos ellos tienen que hacer frente a momentos muy difíciles desde el punto de vista económico.

Luis figura rigiendo el cenobio entre 1318 y 1336, y quizás es el mismo que ocupó el cargo en 1314; tras él actúan Enrique y Pedro. De los últimos priores de origen indudablemente francés destacan Giraldo y Guido. Éste había sido limosnero del cenobio los años anteriores y durante su mandato se desarrolló buena parte de la guerra civil entre Pedro I y Enrique de Trastámara, en especial la célebre batalla de Nájera con el consiguiente saqueo del monasterio ${ }^{32}$. Las consecuencias de esta guerra seguían presentes durante el priorato de Pedro García Diáñez.

Tras Guido, último de nombre francés, rigió el cenobio Juan de Redecilla, natural de la localidad burgalesa de Redecilla del Camino y que posteriormente fue abad de San Millán de la Cogolla ${ }^{33}$. A Fernando le sucedió Rodrigo López, que permaneció en el cargo hasta 1419 cuando fue designado abad del monasterio cluniacense de Sahagún. Las noticias sobre otro prior de nombre Guido son un tanto confusas y, en todo caso, se refieren a los años 1407 y 1420 .

En 1423 comienza el priorato de Pedro Martínez de Santa Coloma, que antes de ocupar este cargo había sido prior claustral y enfermero del cenobio najerense. Durante 30 años figura como prior mayor, aunque en este período hay un documento de 1442 que habla de un prior Pablo; es fácil suponer que se trata de un error del copista,

${ }^{30}$ C. REGLERO DE LA FUENTE, Cluny en España, p. 502; y El monasterio de San Isidro de Dueñas en la Edad Media. Un priorato cluniacense hispano (911-1478). Estudio y colección documental, León, 2005, pp. 179-180.

31 M. CANTERA, Santa María la Real de Nájera, II, doc. 163.

32 Argaiz (Soledad laureada, II, fols. 382 v-383 r) afirma que este prior, a petición del rey Pedro I, dio sepultura en el monasterio a algunos de los caballeros fallecidos en la batalla de Nájera, entre ellos Garcilaso de la Vega. También se sabe que este prior, al igual que hizo el monasterio de San Millán de la Cogolla, entregó en los momentos previos a la batalla parte del tesoro a Garci Pérez de Camargo, por orden del Pedro I, para guardarlo en Burgos temiendo su robo o destrucción; años después el cenobio pleiteó con el citado Garci Pérez hasta conseguir su completa restitución (M. CANTERA, Santa María la Real de Nájera, III, doc. 347).

33 Este hecho nos constata una práctica no extraña en la época, el traslado de monjes de un cenobio a otro, siempre dentro de la misma Orden benedictina, aunque no siempre de la cluniacense. Traslado dentro de la obediencia cluniacense es el caso del prior Rodrigo López, recogido a continuación. El caso contrario, monje emilianense designado prior de Santa María de Nájera es el protagonizado por Gonzalo de Cabredo, como veremos un poco más adelante. 
bien en el nombre, bien en la fecha; en este segundo caso se trataría de Pablo Martínez de Uruñuela. La procedencia de Pedro Martínez está especificada por el de Santa Coloma que acompaña su nombre; se trata de una localidad muy cercana a Nájera y perteneciente al señorío monástico. Durante su priorato se iniciaron las obras de la iglesia del monasterio, que amenazaba ruina y para ello consiguió del papa Eugenio IV, en 1445, la concesión de indulgencias a favor de los que, cumpliendo las condiciones espirituales necesarias, diesen limosna o contribuyesen a su reparación ${ }^{34}$.

Gonzalo de Cabredo "alias de Vergara" era natural de esa localidad guipuzcoana y, según dice fray Juan de Salazar ${ }^{35}$, era "de lo más noble y granado de ella". Desde medidos del siglo XV y hasta principios del XVI en diversos documentos riojanos hay referencias dispersas de individuos apellidados Cabredo, generalmente personajes influyentes, tanto en el ámbito municipal najerense como en el eclesiástico, aunque no se puede constatar el parentesco con el prior ${ }^{36}$. La procedencia geográfica de este prior muestra la extensa área de influencia del cenobio najerense, como veremos con más detenimiento en otro apartado de este trabajo. Designado por el abad de Cluny en 1456, en ese momento era monje de San Millán de la Cogolla, según afirma el papa Calixto II al realizar la provisión del cargo a su favor ${ }^{37}$. Debió de mantener siempre una cierta vinculación con su antigua abadía y en los conflictivos años del final del reinado de Enrique IV intentó apoderarse de dicho monasterio emilianense ${ }^{38}$.

Al poco de acceder al priorato, Gonzalo de Cabredo fue protagonista de un serio intento de agresión movido por su prior claustral y sacristán del monasterio, Martín Sánchez de Arenzana. Este hecho se produjo en la villa de Puerto, en Santoña, donde el cenobio najerense poseía el importante monasterio de Santa María de Puerto, con derechos señoriales y jurisdiccionales sobre dicha villa y numerosas iglesias, monasterios y villas de la región de Trasmiera, donde se encuentra. Las relaciones del cenobio najerense con su dependencia santanderina plantearon con frecuencia problemas

${ }^{34}$ M. CANTERA, Regesta documental, no 130 (solicitud por parte del prior de la indulgencia) y 146 (concesión de la misma). En este marco de rehabilitación de la iglesia seguramente hay que enmarcar el encargo que se atribuye a este prior de un tríptico de Hans Memling, conocido como tríptico de Nájera, adquirido en 1895 por el Koninklijk Museum voor Schone Kunsten de Amberes: tres grandes tablas que representan a Cristo bendiciendo y seis ángeles cantores, en la central; en las laterales cinco ángeles músicos en cada una de ellas. En la iglesia de Santa María de Nájera, las tablas laterales parece que decoraban el órgano; y la central quizás estuvo en el altar; aunque también es posible que las tres estuviesen en el revestimiento del antepecho del órgano (M. CORTI y G.T. FAGGIN, La obra pictórica completa de Hans Memling, Barcelona, 1973, pags. 100-101). De todas formas, dado que este pintor nació en torno a 1435 ó 1440 y que la fecha en que se pintó el retablo se ha fijado en torno a 1480, hay que retrasar la atribución de la compra al siguiente prior, Diego de Garnica; además del argumento cronológico, hay que señalar que en este momento la iglesia ya estaba rehabilitada y se contaba con más dinero para poder adquirir la obra.

${ }^{35}$ Naxara ilustrada, Logroño, 1987, p. 274. Se trata de la transcripción de un manuscrito del siglo XVII.

36 Máximo DIAGO HERNANDO, "Las iglesias propias de monasterios en la Castilla bajomedieval. Algunos ejemplos riojanos", en Hispania Sacra, 49 (1997), pp. 644-645.

37 M. CANTERA, Regesta documental, nº 177 y 181.

38 Máximo DIAGO HERNANDO, "La reforma de los monasterios riojanos en tiempo de los Reyes Católicos”, en Hispania Sacra, 44 (1992), p. 671. 
sobre el cobro de las rentas, el nombramiento y retribución de los beneficiados y, en general, la vinculación con el cenobio najerense ${ }^{39}$.

El intento de agresión se produjo a principios del año 1458, cuando el recién designado Gonzalo de Cabredo acudió a la villa santanderina para visitar el monasterio como señor del mismo y percibir los derechos económicos correspondientes. De acuerdo con las normas cluniacenses, en ausencia del prior mayor era el prior claustral, en este caso Martín Sánchez de Arenzana, el encargado de dirigir y cuidar del monasterio y comunidad najerenses. Sin embargo, este prior claustral, en cuanto supo de la llegada de Gonzalo de Cabredo a Puerto, abandonó sus obligaciones y, desobedeciendo a su prior mayor, se dirigió a las tierras cántabras, en concreto a la localidad de Colindres, para formar un grupo de omes armados de fuste e de fierro, con el que se dirigió de noche a la villa de Puerto con la intención declarada de prender al prior mayor y apoderarse del priorazgo (e lo aver para sy). Si la actuación violenta fracasó fue porque el ruido que hicieron los integrantes del grupo al romper las puertas del monasterio de Santa María de Puerto, donde dormía el prior Gonzalo de Cabredo, le despertó y le permitió escapar por una ventana hasta el monte. Durante casi tres días el prior claustral Martín Sánchez con su grupo armado mantuvo el control del monasterio.

Este hecho lo conocemos porque casi un mes después de acaecido, el 2 de marzo de 1458, el concejo de la villa de Puerto intercedió ante Gonzalo de Cabredo para solicitar el perdón para su prior claustral, considerando su sincero arrepentimiento y su firme voluntad de obedecerle como fijo de obediencia debe ${ }^{40}$. Efectivamente, el prior mayor le concedió el perdón, evitando con ello aplicar el castigo correspondiente a tan grave delito.

El hecho en sí y la narración documental reflejan diversos aspectos. En primer lugar, la hostilidad del prior claustral hacia el prior mayor y su deseo de apoderarse del cargo y priorazgo, lo que quizás descubre una ambición personal truncada por la designación como prior de otro monje que, además, era ajeno a la comunidad najerense $^{41}$. Pero también cabría pensar que en Santa María de Nájera estaba fermentando el deseo de desvincularse de la abadía de Cluny, como se puso de manifiesto en la sucesión del prior Gonzalo de Cabredo; por ello, el abad nombraría prior a un monje ajeno tanto al monasterio como a la Orden. En este caso, si para el abad esta designación era un medio de asegurar la unidad, para la comunidad este prior no dejaba de ser un extraño impuesto para evitar la deseada separación.

En segundo lugar hay que destacar que el prior claustral en rebeldía pudo movilizar un grupo de personas suficiente para llevar a cabo la acción. Si es cierto que no podemos entrever si estos hombres se unieron voluntariamente a él o por dinero, no

${ }^{39}$ Un análisis de algunos de estos aspectos en los años finales del siglo XV en Máximo DIAGO HERNANDO, "Las iglesias propias de monasterios en la Castila bajomedieval", pp. 646-650.

${ }^{40}$ M. CANTERA, Regesta documental, $\mathrm{n}^{\circ} 185$.

${ }^{41}$ Entre 1427 y 1489 hay diversas referencias a un monje llamado Martín Sánchez de Arenzana pero posiblemente fueron tres monjes distintos, dado el amplio marco cronológico comprendido: entre 1427 y 1435 es enfermero; en 1446 se habla de un monje que es bachiller en decretos y que supongo que es el prior claustral y sacristán entre 1457 y 1472, del que ahora hablo; y posteriormente otro que en 1484 figura sólo como monje, y en 1488 y 1489 como cantor. 
podemos descartar la primera hipótesis, dado el deseo de las dependencias cántabras de desligarse de la obediencia y señorío najerenses.

Por último, y en este marco señalado, cabe analizar la actuación del propio concejo de la villa de Puerto. En el texto se señala que Martín Sánchez controló durante tres días la iglesia y monasterio de Puerto contra la voluntad del prior de dicha iglesia y del concejo de la villa. Sin embargo, es poco creíble que si el concejo hubiese estado en contra de la actuación armada, como declaró, no hubiese puesto en marcha una respuesta institucional contra el agresor y que, al tiempo, se lo comunicase a su señor, el prior najerense, para ganar su favor y agradecimiento. Por otra parte, fue el propio concejo de Puerto el que medió ante Gonzalo de Cabredo para que perdonase a su prior claustral, lo que podría indicar una cierta cercanía a éste.

A pesar de que el prior otorgó el perdón solicitado, parece que Martín Sánchez fue privado de sus cargos en el cenobio, pues en 1460 figura como prior claustral y sacristán Pedro Fernández de Soria.

En todo caso, a la muerte de Gonzalo de Cabredo, acaecida el 6 de mayo de 1486, se da el primer paso en el proceso de separación del monasterio respecto a la Orden de Cluny: al día siguiente de fallecer, la comunidad najerense eligió como prior al que en ese momento era prior claustral, Pablo Martínez de Uruñuela sin esperar el nombramiento del $a_{a b d^{42}}$. Éste no podía aceptar una actuación tan contraria a las normas de la Orden y que podía servir de ejemplo a otros monasterios; por ello, ante la rebeldía de los monjes najerenses y de su nuevo prior Pablo Martínez de Uruñuela, designó para el cargo a Diego de Garnica o Diego Martínez de Garnica, monje de ese monasterio. Diego de Garnica intentó tomar posesión del priorato, pero, no atreviéndose a ir a Nájera por la oposición que temía encontrar de los monjes y ciudadanos, ya declarados por don Pablo ${ }^{43}$, se limitó a hacerlo en una de las dependencias del cenobio muy alejada de la ciudad de Nájera, la ermita o monasterio de San Adrián de Sangüesa.

Mientras Diego de Garnica contaba con el apoyo del abad cluniacense, e incluso ganó bulas en su favor ${ }^{44}$, Pablo Martínez de Uruñuela retrasaba la toma de posesión del priorato casi nueve meses, esperando a ver cómo reaccionaban los cluniacenses; sólo lo hizo, el 11 de febrero de 1487, tras obtener del Papa la confirmación del acto $^{45}$. Para asegurar sus derechos y preservar los bienes del monasterio de posibles confiscaciones, tanto de parte de Cluny como de algún laico que podría aprovechar

${ }^{42}$ M. CANTERA, Regesta documental, $\mathrm{n}^{\circ} 264$

43 Ibidem.

${ }^{44}$ El texto utiliza el plural, pero no especifica fechas de concesión o el número concreto de bulas, y lo explica así: viéndose vencido en justicia y que de seguir la apelación por la vía ordinaria, además de estar poco satisfecho de su justicia, se le retrasaban sus intenciones, tuvo amaño de conseguir, con ayuda y favor de los cluniacenses, ciertas bulas sobrecticias y surecticias a su favor respecto al priorato (ibidem).

${ }^{45}$ En el Libro $2^{\circ}$ de censos de Santa María de Nájera (Archivo Histórico Nacional, Clero, leg. 2952; M. CANTERA, Regesta documental, $\mathrm{n}^{\circ}$ 276) se especifica que la bula pontificia fue entregada en mano por el bachiller Pedro Martínez de La Canal, canónigo de Calahorra, letrado que había sido enviado a Roma para defender esta causa. 
en su beneficio esta conflictiva situación, don Pablo solicitó a los Reyes Católicos la confirmación general de todos sus privilegios, que fue concedida en marzo de $1487^{46}$.

Todo este proceso supuso para el monasterio de Nájera una serie de gastos cuantiosos y movió al propio don Pablo a viajar a Roma para frenar la posible influencia de su contrincante y de la Orden de Cluny, así como para promover la separación del cenobio respecto a dicha Orden ${ }^{47}$. La presión ejercida por Pablo Martínez y la comprobación de los fuertes apoyos con que contaba hicieron desistir a Diego de Garnica de sus intentos ${ }^{48}$, de forma que don Pablo quedó en pacifica posesión del cargo.

La vida monástica de este prior que, como indica su apellido, procedía de la localidad de Uruñuela, muy cercana a Nájera, es bastante conocida desde 1457 en que empieza a figurar como monje cantor, ocupando después diversos cargos que marcan un ascenso progresivo en la comunidad: cillerero, tesorero y mayordomo, enfermero y prior claustral hasta ser elegido prior mayor. Vemos constatado, lo mismo en este caso que en el de su predecesor, que el desempeñar el oficio de prior claustral favorecía la designación o elección como prior mayor.

Por otra parte, Pablo Martínez de Uruñuela es el último prior mayor de Santa María de Nájera, pues a partir de 1492, y completando la desvinculación respecto a Cluny, al superior de la comunidad se le llamó abad. La referencia en ese mismo año a Fernando como prior mayor del cenobio parece explicarse como alusión a Fernando Marín de Huércanos, sobrino del citado Pablo Martínez y que, desde 1493, fue abad comendatario de Nájera.

\section{ABAD}

Desde junio de $1492^{49}$, Pablo Martínez de Uruñuela empieza a ser designado abad, confirmando con el título la plena separación de la Orden de Cluny. Ejerció el cargo hasta su muerte, que debió de producirse en los primeros meses de $1508^{50}$.

${ }^{46}$ El mismo Libro $2^{\circ}$ de censos que da la noticia establece dos fechas distintas para esta concesión, el 7 y el 15 de marzo. Este texto general de confirmación otorgado por los Reyes Católicos no se conserva, pero un documento del 26 de junio de 1490 avala su concesión: los Reyes ordenaron a todas las autoridades y concejos que guardasen e hiciesen guardar los privilegios reales que poseía el monasterio y que ellos mismos habían confirmado (M. CANTERA, Regesta documental, $\mathrm{n}^{\circ} 276$ )

${ }^{47}$ Entre los datos recogidos en el citado Libro $2^{\circ}$ de censos tienen cierta entidad los referidos a este viaje y que analizo en el artículo Viaje a Roma de un prior de Santa María de Nájera, en Berceo (en prensa).

48 Unos años más tarde, en 1489, el papa Sixto IV otorgó a este monje la abadía de San Prudencio de Montelaturce, en la misma diócesis calagurritana, en un momento de disensiones sobre la persona que debía ocupar el cargo abacial vacante; se afirma de él que era monje de Santa María de Nájera. Finalmente, tampoco tomó posesión de esta abadía (Francisco Javier GARCÍA TURZA, Documentación medieval de San Prudencio de Montelaturce, Logroño, 1992, doc. 158).

49 M. CANTERA, Regesta documental, n 343.

${ }^{50}$ El 6 de diciembre de 1507 se titula abad por el comendatario, como hace en otros documentos de este mismo año; pero ya en mayo de 1508 se habla de él como el abad anterior (M. CANTERA, Regesta documental, $\mathrm{n}^{\circ} 666$ y 681). 
Junto a él y como abad comendatario figura desde 1501 su sobrino Fernando Marín de Huércanos ${ }^{51}$. Residente en Roma, siempre contó con el beneplácito del papa en los años de enfrentamiento con la Congregación Observante de San Benito de Valladolid por la reforma del cenobio. Permaneció como abad comendatario hasta $1511^{52}$.

Tras asegurarse la incorporación a la Congregación de San Benito de Valladolid, el superior del monasterio se designará con el título de presidente, quedando una vez más el título de abad reservado para el de dicha Congregación.

\section{PRIOR CLAUSTRAL}

Este oficial es el ayudante del prior mayor y le suple cuando está de viaje o enfermo; su misión es de orden interno y disciplinario, vigilando la vida interior del monasterio y sus actividades religiosas ${ }^{53}$. En la lista de monjes su confirmación aparece en primer lugar o inmediatamente después del prior, en caso de figurar éste ${ }^{54}$. Era habitual, y así se comprueba a menudo en el siglo XV, que el ejercer este cargo facilitaba la designación o elección como prior mayor; y asimismo que los que llegaban a él lo hacían tras desempeñar otros oficios monásticos. Tampoco era raro unir a éste otro cargo; así, Pedro era también sacristán, al igual que Roberto, Pedro García Manso de Nestares, Pedro Fernández de Soria, Martín Sánchez de Arenzana y Pedro Martínez de Burgos. En otros casos se unieron los cargos de prior mayor y enfermero, como otro prior Pedro, Pedro Martínez de Santa Coloma, que también fue limosnero, y Pablo Martínez de Uruñuela.

Conocemos el nombre de varios priores claustrales de Santa María de Nájera por testificar en acuerdos, donaciones, arrendamientos u otros actos jurídicos del monasterio; y sobre todo por figurar en la relación de monjes que forman la comunidad monástica y que avalaban o autorizaban algún acto o determinación del prior mayor. De todas formas, la actuación de este prior no se limitaba exclusivamente a ese papel de testigo o de aprobación comunitaria, pues a veces le correspondía la iniciativa de determinadas actuaciones, especialmente en casos de ausencia del prior mayor. También era frecuente su actuación como procurador del cenobio en los pleitos.

La onomástica refleja que durante los primeros años de vinculación del cenobio a la Orden de Cluny, algunos priores claustrales eran de origen francés, como seguramente lo fueron los primeros monjes najerenses. Así, serían franceses Radulfo y

${ }^{51}$ La preocupación de Pablo Martínez de Uruñuela hacia su sobrino se refleja ya en la relación de gastos que el 15 de octubre de 1493 hizo dicho abad (Libro $2^{\circ}$ de censos antes citado), pues recoge, entre otros, 232 mrs. y medio de una zamarra que compró para Fernandico, mi sobrino, para ir a la escuela a leer, 3 reales de un bonete y un real y $124 \mathrm{mrs}$. de un cinto para el mismo.

52 Tanto este proceso de separación respecto a Cluny como la reforma de la observancia monástica en el caso de Santa María de Nájera pueden seguirse en mis artículos: "Santa María de Nájera, un monasterio cluniacense en la Rioja", en II Coloquio sobre Historia de la Rioja, Logroño, 1986, pp. 379-388; y "La incorporación de Santa María de Nájera a la Congregación de San Benito de Valladolid (1496-1513)", en Homenatge a la memoria del Prof. Dr. Emilio Sáez, Barcelona, 1989, pp. 513-519. Y en el de Máximo DIAGO HERNANDO, "La reforma de los monasterios riojanos", pp. 667-697.

53 G. VALOUS, Le monachisme, I, p. 120.

${ }^{54}$ C. REGLERO DE LA FUENTE, Cluny en España, p. 510 
Paris $^{55}$; y podría ser el caso de Roberto y Raimundo. Sin embargo, desde mediados del siglo XIII todos reflejan por el nombre y apellido su origen español y, a menudo, la procedencia de un ámbito cercano a Nájera: Pedro de Bañares, Sancho Garcez, Pedro Martínez de Santa Coloma (luego también prior mayor), Martín Sánchez de Arenzana, Pablo Martínez de Uruñuela (también llegó a ser prior mayor y abad) y Pedro Martínez de Burgos.

Desde 1493, poco después de que el superior del monasterio de Nájera adoptase el título de abad, ejercieron la autoridad en el cenobio un prior (que vendrá a sustituir al prior claustral) y un subprior que, como luego veremos, parece desempeñar las funciones del sacristán. Este último cargo lo ejerció Diego Martínez de Somalo.

Además del prior claustral, el prior mayor podía designar consejeros que le ayudaran en momentos de especial trascendencia; éstos son los denominados socius prior claustralis y vicedominis, citados en 1220 y 1239. En este caso aparecen tres personas desempeñando las dos modalidades de consejeros y, además, uno de los vicedominis ocupaba también un oficio monástico: Martín Pérez era sacristán y Jimeno (Eximinus) era el encargado del vestuario. Éstos eran los llamados en Cluny socii in ordine, adjuntos del prior claustral; eran elegidos entre los monjes más ancianos para asesorar al prior, sin que tuviesen funciones concretas ${ }^{56}$.

\section{CAMARERO O TESORERO}

El camarero, camerarius o tesorero ejercía uno de los oficios más importantes del cenobio, ya que era el administrador de los bienes de la comunidad; aunque siempre bajo la autoridad superior del abad o prior, debía entregar a los monjes el vestido, calzado y ropa de cama en unas fechas fijas del año, y se ocupaba de la iluminación y de lo necesario para los diversos oficios. En dignidad sigue al prior claustral, por encima de los otros oficiales ${ }^{57}$.

En la documentación najerense aparecen los tres nombres señalados para designar este oficio: en el siglo XIII figura como señor del vestuario; y así se denomina a Jimeno tenens vestiarium, Pascual y Gómiz. En el siglo XIV se menciona a Fernando Martínez como camarero ${ }^{58}$.

Finalmente, en el siglo XV se le denomina tesorero, aunque tampoco son muy abundantes las referencias a su actividad: Pablo Martínez de Uruñuela fue tesorero después de ser cillerero y antes de desempeñar los oficios de enfermero, mayordomo, prior claustral, prior mayor y, finalmente, abad. Por su parte, Fernando Martínez de Azofra ejerció este cargo después de muchos años de formar parte de

${ }^{55}$ En 1228 un monje Paris figura como prior claustral de Carrión (C. REGLERO DE LA FUENTE, Cluny en España, p. 511). No se puede saber si se trata del mismo.

56 C. REGLERO DE LA FUENTE, Cluny en España, p. 512.

57 G. de VALOUS, Le monachisme, I, pp. 124-128. Hay que diferenciar este camarero o tesorero del monasterio del camarero de la Orden en España, cargo que con frecuencia desempeñó el prior de Nájera, al menos en los primeros tiempos de vinculación a la abadía francesa.

58 M. CANTERA, Santa María la Real de Nájera, II, docs. 152 (año 1239), 158 (año 1258), 183 (año 1273); y III, 412 (1396), respectivamente. 
la comunidad monástica; y posteriormente siguió figurando en la documentación najerense como monje.

\section{SACRISTÁN}

Éste es uno de los oficios monásticos más destacados en la Orden de Cluny por la gran importancia que tiene en ella la liturgia: el sacristán es el encargado de tener preparados todos los objetos necesarios para el culto (vasos sagrados, libros litúrgicos, vestiduras para los sacerdotes, velas, óleo, etc.), siendo por tanto custodio de los objetos sagrados, que a menudo tenían gran valor económico, así como también de los documentos del monasterio. También debía dirigir ciertas funciones litúrgicas y era el encargado de tocar las campanas, que marcan el ritmo de vida del monje ${ }^{59}$.

Para hacer frente a los gastos derivados de su oficio, el sacristán najerense disponía de recursos propios: heredades, huertas, sernas y derechos económicos que cobraba en determinadas villas; también poseía viñas, de las que se obtendría el vino necesario para la liturgia. A ellos se une la villa de Alesón que donó el rey Alfonso I el Batallador para la iluminación del altar de Santa María en el monasterio ${ }^{60}$. Aunque el sacristán gozaba de cierta autonomía en la gestión de ingresos y bienes de su oficio, debía rendir cuentas de todo ello al menos dos veces al año ${ }^{61}$.

La importancia de este oficio dentro de la comunidad se refleja en las numerosas referencias documentales al sacristán; así, es habitual que su nombre se incluya, y entre los primeros oficiales, en la relación de los miembros de la comunidad avalando actos jurídicos (especialmente ventas, cartas de procuración, etc.). Como en otros cargos, las menciones de sacristanes en los años iniciales de su vinculación a Cluny, aproximadamente hasta 1222, reflejan el origen francés de muchos de ellos.

A partir de 1484 desaparecen las referencias a este cargo. Esto se puede explicar porque, dada la frecuente relación que desde el siglo XIII existía entre los cargos de prior claustral y sacristán, cuando el monasterio se desvinculó de la Orden de Cluny y el antiguo prior tomó el título de abad, las funciones propias del sacristán las desempeñaría el subprior.

En algunas ocasiones se habla de sacristán mayor, lo que indica que junto al responsable principal habría otro que se ocuparía de los aspectos más cotidianos y elementales, bajo la supervisión de ese sacristán mayor. Y, efectivamente, hay un documento de 1201 que recoge los nombres de un sacristán mayor (Pedro) y de un sacristán menor (Juan) ${ }^{62}$.

59 G. de VALOUS, Le monachisme, I, p. 148.

${ }^{60}$ M. CANTERA, Santa María la Real de Nájera, II, doc. 30; y Colección documental, doc. 30. La donación fue confirmada por Alfonso VIII en 1135 (doc. 42). Reglero de la Fuente (Cluny en España, pp. 512-513) añade otras propiedades que fueron donadas bajo la fórmula ad ipsum altare de Sancte Marie de Nazarensis propter luminarie, o semejantes, por hacer referencia a la iluminación del altar, función que correspondía al sacristán; de todas formas, sólo en el caso de Alesón se especifica con rotundidad la vinculación a la sacristanía.

${ }^{61}$ Así lo establecieron los visitadores en 1245 (M. CANTERA, Colección documental, doc.153).

62 M. CANTERA, Santa María la Real de Nájera, II, doc. 103. 


\section{LIMOSNERO}

El oficio de la limosnería ${ }^{63}$ nació del deseo y el deber de practicar la caridad, deber de todos los cristianos, pero que llegó a su máxima expresión entre los monjes, para quienes era una de las principales ocupaciones de su vida. De esta obligación habla la Regla de San Benito en varios pasajes, entre los que destaca el que dice pauperum et peregrinorum maxime susceptione cura sollicite exhibeatur, quis in ipsis magis Christus suscipitur ${ }^{64}$. Esta idea, tratar al pobre y al peregrino como si fuese Cristo en persona, marca la pauta de la acogida y atención de los necesitados y se muestra ya en el documento fundacional de Santa María, pues el rey García III lo dotó convenientemente, afirmando que lo hacía para que tuviesen lo suficiente para comer y vestir tanto los que allí se habían de encargar del culto divino, como peregrinis seu hospitibus, quia in utriusque suscipitur Christus ${ }^{65}$.

El limosnero cluniacense era el oficial encargado de acoger y dar alimento a los pobres y de distribuir entre ellos lo que sobraba de la mesa de los monjes. Debía dar hospitalidad a los peregrinos y viajeros humildes, presbíteros y religiosos que estaban de paso, y a todos los pobres que acudiesen al monasterio a pedir cuidado y comida. Pero, además, el limosnero cluniacense debía recorrer cada semana, ayudado por un sirviente, las casas de los enfermos pobres para atenderles en lo necesario ${ }^{66}$.

Al monasterio acudía un número determinado de pobres que, en ciertos días del año, recibían una cantidad mayor de alimento; en otras ocasiones se incrementaba el número de personas asistidas. Así, cuando en 1140 García Fortúñez y su mujer donaron al cenobio najerense el monasterio de San Jorge de Azuelo, en Navarra, establecieron que a su muerte se celebrase en la iglesia del monasterio de Nájera su aniversario y se diese de comer pan, vino y carne a 30 pobres. Una labor de asistencia caritativa que se mantuvo a lo largo de los siglos, y que hizo exclamar a uno de los donantes de bienes al cenobio que con ese gesto deseaba agradecer el haber sido criado a la almosna de Sant George (de Azuelo) ${ }^{67}$.

El recibimiento de los pobres y la liturgia en torno a ellos estaban perfectamente establecidos en la Orden de Cluny, correspondiendo al limosnero ser representante del abad y del convento de cara a los necesitados; por ello, entre sus funciones figuraba la dirección del hospital o domus pauperum, alberguería o domus helemosine ${ }^{68}$. Santa María de Nájera poseía desde antes de su integración en Cluny una alberguería, que había sido ricamente dotada por el monarca navarro García III unos meses antes

63 Sobre este oficio publiqué hace años un artículo: El oficio de la limosnería en Santa María la Real de Nájera (siglos XI-XV), en En la España Medieval. IV. Estudios en memoria del profesor D. Ángel Ferrari, Madrid, Universidad Complutense, 1984, pp. 175-182.

${ }^{64}$ Capítulo 53, versículo 15.

65 M. CANTERA, Santa María la Real de Nájera, II, doc. 10; y Colección documental, doc. 10.

${ }^{66}$ G. de VALOUS, Le monachisme, I, p. 163; M. MOLLAT, "Les moines et les pauvres, XI"- XII" siècles", en Monachesimo e la riforma ecclesiatica (1049-1122). Atti della quarta settimana internazionale di studio, Mendola, 23-29 agosto 1968, Milán, 1971, p. 201.

${ }^{67}$ M. CANTERA, Colección documental, doc. 51 (documento de 1140); y Santa María la Real de Nájera, II, doc. 159 (documento de 1259), respectivamente.

68 M. MOLLAT, "Les moines et les pauvres, p. 204. 
de la fundación de la propia iglesia ${ }^{69}$. La alberguería ejercería las funciones de hospital (y así se le denomina posteriormente, alternando este nombre con el propio de alberguería) y de albergue para peregrinos, ya que Nájera se encuentra en el Camino de Santiago.

Aunque la alberguería era anterior a la incorporación a Cluny, este hecho determinó la organización del oficio monástico de la limosnería, dotado de recursos propios; y es a partir de ese momento cuando empiezan las referencias al limosnero, como testigo o como integrante de la comunidad monástica en los actos jurídicos. Rara vez se compartía este oficio con otra responsabilidad en el cenobio, posiblemente por tratarse de una actividad que requería plena dedicación. Uniendo dos oficios sólo está documentado el caso de Pedro, que a finales del siglo XIV era prior claustral al tiempo que limosnero. Este hecho posiblemente se pueda explicar porque en esos años el monasterio tenía un número tan escaso de monjes, que fue necesario "concentrar" responsabilidades.

Cuestión distinta es que el monje encargado de la limosnería hubiese desempeñado o ejerciese después algún otro oficio; así, Juan Martínez de San Millán antes de ser limosnero había sido mayordomo, lo mismo que Pedro Martínez de Tobía; y Pedro Martínez de Burgos ejerció sucesivamente los oficios de mayordomo, limosnero, prior claustral y sacristán, y finalmente prior mayor.

Las referencias ocasionales a limosnero mayor, que es el que figura como destacado miembro de la comunidad, nos indica que habría otro u otros limosneros menores, reflejo de la intensa actividad de este oficio.

En la Orden de Cluny, además del limosnero, encargado de la atención a los pobres, existía un oficio de hospitalario u hospitalero, el custos hospitum, que recibía a los huéspedes y peregrinos ricos. Sin embargo, en el monasterio de Nájera no hay ninguna noticia de este oficio, y seguramente sus funciones no se separaron de las que ejercía el limosnero.

\section{ENFERMERO}

El enfermero era el oficial encargado de cuidar de la salud corporal de los monjes, para ello disponía de un edificio propio o de ciertas estancias dentro del recinto monástico, la enfermería, así como de un espacio en la huerta para el cultivo de plantas medicinales. Mientras estaban en la enfermería, los monjes mantenían una existencia separada del resto de la comunidad; y hasta disponían de un oratorio propio.

La primera noticia de la enfermería de Santa María de Nájera es del año 1201, cuando el prior Jimeno procedió a su restauración y la de su claustro anejo, pues ambos habían sido destruidos por el fuego. Pocos años más tarde, Diego López de Haro

${ }^{69}$ M. CANTERA, Colección documental, doc. 9; esta donación fue confirmada por Alfonso X en 1272 y por Alfonso XI en 1328 (M. CANTERA, Santa María la Real de Nájera, II, doc. 175; y III, doc. 251). Sobre la alberguería publiqué un trabajo: "La alberguería de Santa María la Real de Nájera (siglos XI-XV)", en Anuario de Estudios Medievales, 12 (1982), pp. 367-380. 
mandó construir un edificio nuevo, al tiempo que le entregaba bienes cuya administración, por deseo explícito del donante, correspondía en exclusiva al enfermero ${ }^{70}$.

En cuanto a los monjes que desempeñaron el oficio los conocemos generalmente por figurar en actuaciones de escasa relevancia y protagonismo, siendo testigos o confirmantes de actos del monasterio; o por aparecer en la relación de oficiales de la comunidad. Con cierta frecuencia recibieron el encargo de actuar como procuradores del monasterio.

No es frecuente unir este oficio a otro, aunque sí lo hizo Lope, que en 1226 era también mayordomo; y a principios del siglo XV Pedro Martínez de Santa Coloma, al tiempo prior mayor del cenobio. Para otros monjes, este cargo fue una etapa intermedia en el desempeño de los oficios monásticos: Martín Sánchez de Arenzana fue prior claustral y sacristán tras ser enfermero; Pedro Sánchez de Villanueva alternó este oficio con otros de carácter económico, como los de clavero y mayordomo de la obra; y Pablo Martínez de Uruñuela fue enfermero tras ser tesorero y cillerero, y antes de ser designado prior mayor y, finalmente, abad. Pedro Sánchez de Cárdenas, por su parte, pasó de este oficio al priorato de San Vicente de Salamanca, por designación del abad de Cluny ${ }^{71}$.

\section{MAYORDOMO Y CILLERERO}

Los oficios de mayordomo y cillerero son parecidos, estando encargados de proporcionar los alimentos, de reponer los utensilios de la cocina y refectorio y, en general, de la economía doméstica ${ }^{72}$. Para hacer frente a los gastos propios de su actividad, la cocina del monasterio disponía de recursos económicos propios, entre ellos parrales y majuelos.

En la documentación najerense aparecen generalmente como oficios diferentes, y por ello los ejercieron dos monjes distintos al mismo tiempo ${ }^{73}$; pero en el siglo XV es habitual que el mismo oficial sea designado en unas ocasiones mayordomo y en otras cillerero o, incluso, mayordomo y cillerero a la vez, señalando la diferencia de los oficios, aunque los ejerciese la misma persona. Éste es el caso de Juan García, Martín Fernández de Moreda, Diego Martínez de Somalo y Juan Sánchez de Baños, que ven alternar en su designación los dos cargos, aunque son más frecuentes las referencias a mayordomo; en otras ocasiones, los citados Diego Martínez de Somalo y Juan Sánchez de Baños figuran uniendo los dos oficios.

Hay también otras denominaciones para este cargo: en 1175 se habla de cellerarius coquinae (cillerero de la cocina); en 1290 de pitancero; y en 1508 de despensero.

Cabe constatar que el de mayordomo es quizás uno de los oficios que con más frecuencia aparece en la documentación, siendo rara la relación de la comunidad monástica en que no se incluya a este oficial.

${ }^{70}$ M. CANTERA, Santa María la Real de Nájera, II, docs. 105 y 113 respectivamente.

71 M. CANTERA, Regesta documental, nº 153.

72 José GARCÍA GONZÁLEZ, Vida económica de los monasterios benedictinos en el siglo XIV, Valladolid, 1972, p. 40; VALOUS, Le monachesisme, I, pp. 131 y ss.

73 Así, en 1488 Juan Sánchez de Baños es mayordomo y Pedro Fernández de San Millán es cillerero. 
La importancia del oficio de mayordomo o cillerero explica la existencia de un ayudante, el subcillerero o submayordomo, encargado especialmente del servicio de la cocina y de dirigir a los sucesivos cocineros del monasterio, ya que en la Orden de Cluny todos los monjes debían ir rotando en este servicio; también estaba encargado de cuidar los utensilios de la cocina ${ }^{74}$. Este cargo debe corresponder al procurator coquine y al sennor de la cozina de varios documentos del siglo XIII.

Junto al mayordomo del monasterio, en una sola ocasión de habla de un mayordomo del abad; se trata de Juan de Mijancas, que había sido criado del abad Pablo Martínez de Uruñuela y posteriormente su mayordomo. La existencia como oficio propio refleja la separación de mesas (separación de bienes) de la comunidad y del abad.

\section{REFITOLERO}

El refitolero es el oficial encargado del refectorio, bajo la dirección del cillerero y asistido por tres monjes. Sin embargo, sólo en dos ocasiones aparece este oficio en la documentación najerense, cuando los monjes que lo desempeñaban actuaron como testigos de determinados actos jurídicos.

\section{OBRERO O MAYORDOMO DE LA OBRA}

La importancia de las obras que se realizaron en el monasterio de Nájera desde mediados del siglo XV justifica la aparición de este oficio, ejercido por dos monjes a lo largo de treinta años: Sancho Sánchez de Villanueva y Juan Martínez de Cirueña. El título completo con el que figura el primero es el de mayordomo de la obra nueva, obrero, administrador de la fábrica y capillas.

\section{SOCHANTRE O ARMARIUS Y CANTOR}

Este oficial tenía función litúrgica: era el maestro de coro y de ceremonias. En los primeros tiempos, en Cluny se diferenciaba el sochantre, o jefe de los chantres, y el armarius, guardián de los libros y maestro de ceremonias propiamente dicho, de superior categoría que el anterior. En algunos monasterios ambas funciones las ejercía el mismo monje y en otros era el sacristán quien se encargaba de ellas ${ }^{75}$.

Sólo en dos ocasiones a principios del siglo XIII se habla del armarius del monasterio najerense. Pero posiblemente responde también a esta dignidad el título de cantor que aparece con más frecuencia desde mediados del siglo XIV y, de forma especial, en el XV. Incluso en ciertas ocasiones se habla de cantor mayor y de un socantor, lo que nos indica, aparte de un crecimiento de la comunidad monástica, la importancia de su oficio que requería de algún ayudante (hay que recordar la solemnidad con que se celebraba la liturgia en la Orden de Cluny).

\footnotetext{
74 VALOUS, Le monachisme, I, pp. 135-136.

75 Ibidem, I, pp. 156-137. El nombre de armarius procede del armarium o mueble donde se guardaban dichos libros.
} 


\section{CLAVERO Y PORTERO}

El claviger o clavero debía ser el encargado de custodiar las llaves del monasterio. Casi siempre, se le denomina clavero del prior, lo que indicaría una vinculación con este monje.

Por otra parte, el portero tendría como función vigilar las puertas del cenobio. En la documentación del siglo XV este oficio aparece siempre unido a criados del prior o abad, y casi nunca a monjes, lo que indica posiblemente la pérdida de importancia del puesto, que sería desempeñado por personas ajenas a la comunidad de los monjes, aunque vinculadas al monasterio de forma más o menos directa. El único caso documentado de un monje que ejerció ese cargo es Juan Fernández; en otro documento de fecha cercana se alude a un portero y criado del prior con ese mismo nombre, pero, como no se indica su condición de monje, pienso que se trata de otra persona.

\section{EL CONVENTO Y EL CAPÍTULO CONVENTUAL}

El convento lo componían el prior (luego abad), los oficiales y todos los otros monjes que no poseían cargo en el cenobio; así, desde que Santa María de Nájera fue donado a Cluny en 1076 se empieza a hablar de monasterio de monjes. Por otra parte, la expresión convento no aparece hasta 1183 , pero desde entonces es más frecuente y habitual. Así se habla de conventui monachorum Sancte Marie Naiare y, desde el siglo XIV, su traducción castellana, convento de los monges de Santa María de Nágera. A partir de ese momento la palabra monasterio parece designar el edificio y los bienes materiales, mientras que convento sería la comunidad monástica que vivía en aquél y que gozaba de personalidad jurídica propia.

El capítulo conventual era la asamblea formada por todos los monjes profesos y presidida por el prior, o abad en su momento; se celebraba en la llamada sala capitular, situada en el claustro cerca de la iglesia. En la reglamentación de la Orden de Cluny se establecía la obligación de que se reuniese a diario en los monasterios de más de seis monjes, y dos o tres veces por semana en los demás ${ }^{76}$.

El capítulo, que se celebraba antes de Primas, constaba de tres partes: la primera era litúrgica, con ciertas oraciones y la lectura de un capítulo de la Regla de san Benito, que comentaba el superior (lectura que da el nombre a la asamblea); después se trataba de la administración temporal del cenobio, momento en que los diversos oficiales daban cuenta de sus actuaciones; y la última parte era de carácter disciplinario, y en ella los monjes exponían sus faltas en el cumplimiento de la Regla y la vida conventual, tras lo cual se señalaba el castigo merecido por las mismas. De esta forma, el capítulo unía la misión consultiva que le atribuyó san Benito y una función jurídica precisa, como es la aprobación de determinadas actuaciones del prior que necesitaban de este aval para que fuesen válidas ${ }^{77}$.

En la documentación najerense se habla de capitulo de Nagera ya a mediados del siglo XII, pero será en el XIV cuando aparezca la fórmula más precisa [prior y otros

76 VALOUS, Le monachisme, I, pp. 213-223.

77 José MATTOSO, Le Monachisme ibérique et Cluny, Lovaina, 1968, p. 211. 
oficiales] e el convento de los monjes del dicho monasterio de Santa María de Náje$r a$, seyendo ayuntados en nuestro capildo segunt lo hemos de uso e de costumbre. El lugar de celebración del capítulo se cita sencillamente como en la clastra del dicho monasterio, hasta que a partir de 1442 el lugar habitual era la capilla de Santa Catalina, lugar que es diputado capitular, y en la cual ya se celebró una reunión en 1416. En 1431 hay una referencia a otra que tuvo lugar en el claustro, ante las puertas de la capilla de la reina doña Mencía. Como excepciones se celebraron algunos capítulos en la capilla de San Benito y en los palacios priorales ${ }^{78}$.

El mando supremo en la comunidad, como ya he dicho, correspondía al prior, luego abad. Pero su poder no era ilimitado y necesitaba del consentimiento de los monjes para ciertos asuntos importantes. Así, desde 1183 aparecen en la documentación expresiones como cum assensu totius conventus, cum assensu et volumptate tocius conventus, de consensu et convenientia conventum, con consentimiento e otorgamiento del convento de dicho monasterio. Como ejemplo, en 1220 la comunidad declaró su acuerdo con las actuaciones que el prior estaba llevando a cabo en el pleito con el obispo de Calahorra ${ }^{79}$.

Se puede constatar cierta autonomía entre prior y convento, pues ya a principios del siglo XIII tenían sellos y archivos separados. Pese a ello, siempre se otorga una cierta supremacía al prior, que debía autorizar los actos realizados por su comunidad; así se constata cuando en 1355, estando el prior mayor Pedro ausente del monasterio (residía temporalmente en Logroño), dio permiso al prior claustral y al convento para recibir una donación y realizar los tratos que para ello fuesen necesarios ${ }^{80}$. Aunque también el prior estaba sometido al control de su comunidad y, tal como establecieron los visitadores en 1245, debía rendir cuentas dos veces al año de los gastos realizados e ingresos obtenidos ${ }^{81}$.

Respecto a la organización económica del monasterio, y como ya he dicho en otro momento, algunos oficios disponían de bienes propios para hacer frente a los gastos derivados de su actividad; es el caso del hospedero, el enfermero y el limosnero. A pesar de ello, el prior siempre conservó un cierto control y responsabilidad superior sobre dicha administración.

Por otra parte, en Cluny había separación de la gestión económica en dos mesas, la del prior/abad y la del convento. Esta diferencia, sin embargo, pocas veces se refleja en la documentación najerense, pues sólo en dos ocasiones, y en fechas muy cercanas, se nos habla de la mesa de los monjes; fue Diego López de Haro, quien al hacer sendas donaciones indicó que iban destinadas ad opus mensae seniorum ${ }^{82}$. Esta separación podría también traslucir una mutua desconfianza, aunque quizás mayor de la comunidad hacia su superior, temiendo especialmente un abuso de poder y la malversación de los bienes que necesita el monasterio para vivir.

78 M. CANTERA, Regesta documental, no. 78 (25 marzo 1416); 119 (1 septiembre 1431); 224 y 225 (7 mayo 1476); y 247 (24 agosto 1479).

79 M. CANTERA, Santa María la Real de Nájera, II, doc. 129.

${ }^{80}$ M. CANTERA, Santa María la Real de Nájera, III, doc. 306.

${ }^{81}$ M. CANTERA, Santa María la Real de Nájera, II, doc. 153

${ }^{82}$ M. CANTERA, Santa María la Real, II, docs. 102 (año 1200) y 113 (año 1214), respectivamente. C. REGLERO DE LA FUENTE, Cluny en España, p. 548. 
Una patente muestra de esta desconfianza es la afirmación del donante en el segundo de los documentos citados: el conde afirmaba que le movía a realizar ese acto el saber que los monjes vivían en una situación de penuria, estando incluso algunos enfermos, y que nadie se ocupaba de ellos; y completaba la afirmación con una mención explícita: ni siquiera el prior (nec priorem...curam habeat). Así, pues, por ese deseo de ayudarles, pero también de evitar que el prior pudiera beneficiarse de los dones que iba a entregar, especificaba a qué oficios vinculaba cada uno de los bienes (enfermería, vestuario, cocina iluminación del altar); y para completarlo, establecía que el oficial correspondiente era el único que podía administrar dichas propiedades, y que ni el abad de Cluny ni ninguna otra autoridad eclesiástica podían cambiarlos de destino.

No es la última vez que la familia Haro tuvo que ayudar a la comunidad enfrentada con su superior. Así, hacia 1230 los monjes acusaron a su prior Juan de destruir y alienar parte del patrimonio monástico (distractiones seu alienationes), provocando importantes pérdidas económicas y elevadas deudas ${ }^{83}$; según se deduce, las enajenaciones se produjeron sin el consentimiento de la comunidad, cuando la consulta era preceptiva por la elevada cuantía de algunas. También se acusaba al prior de falsificar las cuentas. La situación económica en que estaba el monasterio cuando marchó este prior era tan dramática que los monjes no tenían ni siquiera pan y vino, y tuvieron que suplicar la ayuda de don Lope de Haro (postrabit se ad pedes domni Lupi) para poder sobrevivir. No sabemos si el prior Juan contestó a esta demanda y pudo justificar su gestión; en todo caso, es evidente el descontento de la comunidad, más bien, el total rechazo hacia su forma de actuar.

Si a través de esos hechos podemos pensar que las relaciones entre los monjes y el prior no siempre fueron fáciles, hay otros acontecimientos que lo ratifican, como el informe ya citado que el prior Jimeno redactó a principios del siglo XIII dando cuenta de su actuación al frente del monasterio para defenderse de las acusaciones surgidas dentro de la comunidad ${ }^{84}$.

Reflejo indudable de las malas relaciones, al menos en ciertos momentos o entre ciertos monjes, es el mencionado intento de agresión al prior Gonzalo de Cabredo por parte de su prior mayor. Y no es la primera vez que se produjo una desobediencia importante, al menos de la que tenemos noticia, pues ya en 1269 se habla de unos monjes que se habían aliado contra el prior $^{85}$.

\section{NÚMERO DE MONJES}

El número de monjes que vivía en los monasterios variaba mucho de unos cenobios a otros y, en buena medida, dependía de las posibilidades económicas en cada caso y

${ }^{83}$ M. CANTERA, Colección documental, doc. 151. C. REGLERO DE LA FUENTE, Cluny en España, p. 549.

${ }^{84}$ M. CANTERA, Santa María la Real de Nájera, II, doc. 105. C. REGLERO DE LA FUENTE, Cluny en España, p. 547. El prior subrayaba que siempre había intentado complacer a los seniores y socios suyos de Nájera.

${ }^{85}$ C. REGLERO DE LA FUENTE, Cluny en España, p. 621 
circunstancia concreta. En la Orden de Cluny la comunidad solía ser numerosa por la prolongación de los oficios litúrgicos, motivo por el cual también era frecuente que muchos de los monjes recibiesen las órdenes sagradas ${ }^{86}$.

Parece ser que en Nájera el número reglamentario era de treinta monjes. Pero desde fines del siglo XIII, y sobre todo en el XIV esta cifra nunca se llegó a alcanzar; esto refleja la decadencia del cenobio, así como la pérdida de atracción de la vida monástica ante otras formas de expresión religiosa, especialmente la desarrollada por las Órdenes mendicantes. Así, en 1258 había 18 monjes y el prior; en 1292 eran 16 y el prior; y en 1387 y 1392 sólo había 10 monjes.

Sin embargo, en el siglo XV podemos hablar de una recuperación del cenobio en todos los aspectos y, en concreto, de un aumento considerable del número de monjes: en 1460 son 18 los monjes, además del prior y dos novicios ${ }^{87}$. Esta cifra, con pequeñas oscilaciones, se mantuvo en adelante de forma casi constante, e incluso se superó, como podemos deducir de la relación de monjes recogida en diversos documentos: en 1435 se da el nombre completo de 17 monjes, añadiendo y todo el convento reunido; aunque esta frase puede parecer formularia y nos hace pensar si realmente había más monjes aparte de los nombrados, hay otros documentos en los que no se añade, de modo que su inclusión o no haría referencia a una realidad.

A finales del siglo XV la comunidad creció aún más: en 1484 se da el nombre de 19 monjes; en 1496, de 23; y en 1501, de $22^{88}$. En ninguno de estos casos se incluye la coletilla y todo el convento o y los otros monjes, lo que parece indicar que se trataba de toda la comunidad monástica. Queda de manifiesto la recuperación en el número de monjes, lo que hizo posible la observancia fiel de la liturgia propia de la Orden cluniacense, tal y como los testigos afirmaban que ocurría en esa etapa, cuando se promovía la vinculación del cenobio a la Congregación Observante de San Benito de Valladolid.

El ingreso en el monasterio podía producirse a temprana edad, como parece indicar la referencia a los infantes Martín de Arenzana ${ }^{89}$, Pedro de Mahave o Diego de Cárdenas.

Lo habitual era que la permanencia de los monjes en el cenobio terminase sólo con la muerte. De todas formas, hay que señalar que la norma de la estabilidad monástica en Cluny no se entendía obligatoriamente como permanencia en el mismo monasterio, sino en la comunidad cluniacense; es decir, en los monasterios que formaban parte de la Orden. Por ello, los monjes podían desplazarse de uno a otro cenobio, con la preceptiva autorización del abad, el camarero de la Orden o el prior del propio monasterio.

${ }^{86}$ Giles CONSTABLE, Monastic tithes. From their origins to the twelfth century, Londres, 1964, pp. 145-149.

${ }^{87}$ Ulysse ROBERT, "Etat des monasteres espagnols de l'Ordre de Cluny, aux XIII'-XVe d'apres les actes des visites et des chapitres généraux", en Boletín de la Real Academia de la Historia, XX (1892), pp. 321-431.

${ }^{88}$ M. CANTERA, Regesta documental, $\mathrm{n}^{\circ} 131$ (26 abril 1435), 261 (31 julio 1484), 438 (2 agosto 1496) y 555 (28 febrero 1501), respectivamente.

${ }^{89}$ Curiosamente, en el documento de 1435 en que figura un infante así llamado, también hay un monje con el mismo nombre (M. CANTERA, Regesta documental, $\mathrm{n}^{\circ}$ 131). Las referencias a los tres infantes se realiza en este mismo documento. 
Esta movilidad parece confirmada por la homonimia de monjes en los diversos cenobios, en años diferentes, aunque próximos; y, desde luego, está constatada en el caso de los priores ${ }^{90}$. De modo especial está documentada la movilidad de monjes entre Nájera y Carrión a principios del siglo XIII, cuando Juan era prior simultáneamente de ambas casas $^{91}$. También sabemos que un monje najerense, Pedro Sánchez de Cárdenas, fue designado prior de San Vicente de Salamanca por el abad Odón dejando vacante el oficio de la enfermería que desempañaba ${ }^{92}$.

En otras ocasiones, sin embargo, el desplazamiento era una medida disciplinaria para castigar faltas graves, como la incontinencia o la rebeldía. Éste es el caso antes señalado de los monjes que en 1269 se habían rebelado contra el prior y a los que se castigó con el traslado ${ }^{93}$.

También tenemos noticias de cambios voluntarios y solicitados por los interesados. Así, a mediados del siglo XIII, Gonzalo, un monje criado desde su niñez en San Zoilo de Carrión, a petición propia marchó a Cluny, tras pasar por Nájera ${ }^{94}$.

Más tardía, principios del siglo XV, es la súplica que dos monjes profesos de Nájera, Pedro Martínez de Santa Coloma y Pedro Pérez de Belorado, elevaron al papa Martín $\mathrm{V}$ para retirarse al monasterio de Santa María de Valvanera, perteneciente a la misma Orden de san Benito y diócesis calagurritana que el de Nájera, pero situado en un lugar solitario y más tranquilo ${ }^{95}$. En la petición explicaban que el cenobio najerense está en el Camino de Santiago, frecuentado por peregrinos de diversas partes del mundo, de forma que siempre había movimiento de personas seculares; a ello se unían certas alias causas legitimas circa divina, lo que posiblemente se refería a la actividad intensa que en el monasterio najerense debían de desarrollar los monjes para dirigir y atender su gran y extenso dominio económico, con salidas frecuentes del claustro para supervisar la explotación, cobrar o renovar los arrendamientos, emprender y seguir los pleitos con vecinos o concejos vasallos, o con los colindantes, y otras muchas obligaciones que les alejarían del silencio y apartamiento del mundo que deseaban en la vida monástica; por el contrario, en el cenobio de Valvanera, "perdido" en la soledad de la montaña, la Sierra de San Lorenzo, sería más fácil encontrar el retiro monástico que deseaban.

La fórmula fiat pro utroque supone la concesión de su súplica. Sin embargo, no podemos asegurar que el traslado se produjese, ya que en la documentación del cenobio de Valvanera de los años siguientes no figura ninguno de los dos monjes; de todas formas, es posible que Pedro Pérez de Belorado sí se marchase a Valvanera, ya que no vuelve a figurar en la documentación najerense ${ }^{96}$.

${ }^{90}$ C. REGLERO DE LA FUENTE, Cluny en España, pp. 537-538. Podríamos incluso hablar de un cursus honorum que supondría ir ascendiendo al cargo de prior de monasterios cada vez más importantes por el nivel de rentas y con una comunidad de monjes más numerosa.

91 C. REGLERO DE LA FUENTE, Cluny en España, p. 538.

92 M. CANTERA, Regesta documental, no 153.

93 C. REGLERO DE LA FUENTE, Cluny en España, p. 621.

94 Ibidem.

95 M. CANTERA, Regesta documental, no 94 (14 julio 1419): quod in heremo et silvis ac gravibus altitudinibus et montaneis et solitidinibus situatum.

${ }^{96}$ Las referencias a este monje en los documentos de Santa María de Nájera se producen a partir de 1410 como testigo de diversos actos o formando parte de la comunidad monástica, aunque en alguna ocasión es nombrado sólo como Pedro Pérez. 
Más complejo es el caso del otro solicitante, Pedro Martínez de Santa Coloma; éste es el nombre del prior claustral de Nájera entre 1404 y 1423, luego prior mayor desde 1425 hasta su muerte en 1453. Es imposible discernir si el monje que quería trasladarse a Valvanera era éste u otro con el mismo nombre; si la coincidencia de nombres no es imposible, el hecho de que el Pedro Martínez que solicitaba el traslado fuese sacerdote, me inclina a pensar que es la misma persona, ya que en la Orden de Cluny era norma que el prior mayor fuese sacerdote, cuando no todos los monjes (ni siquiera la mayoría) recibían órdenes mayores. Sin embargo, es extraño que no se hiciese constar en la súplica que desempeñaba el cargo prioral, si efectivamente se trataba de él, y que se mantuviese en él tras mostrar su deseo de marchar de este cenobio, aunque finalmente no se trasladase.

En este caso también queda de manifiesto que el desplazamiento no sólo se producía entre monasterios cluniacenses, sino que se ampliaba a toda la familia benedictina.

Así, consta que en 1489 dos monjes najerenses fueron nombrados abades de otro monasterio, en este caso el de San Prudencio de Montelaturce, de la Orden del Císter $^{97}$ : el primero propuesto para el cargo abacial fue Fernando Díez o Díaz de Zarratón, que renunció antes de ser confirmado por el papa; el segundo es Diego de Garnica, que también abandonó el cargo ante los conflictos surgidos por su nombramiento ${ }^{98}$.

Pero más elocuente es el caso del prior Gonzalo de Cabredo, del que se afirma expresamente que era monje de San Millán de la Cogolla99; y pienso que también podrían proceder de este mismo cenobio Francisco de San Millán (1488-1503), Juan Alfonso de San Millán (1420-57), Juan de San Millán (1465-1500), Juan Martínez de San Millán (1405-36) y Pedro Fernández de San Millán (1479-98), según indicaría su nombre.

\section{PROCEDENCIA GEOGRÁFICA DE LOS MONJES DE SANTA MARÍA DE NÁJERA}

Como he señalado al hablar de los priores del monasterio, la primera comunidad najerense procedía de Francia y muchos de dichos priores, designados por el abad de Cluny, fueron franceses, al menos hasta el siglo XIV, como reflejan sus nombres: Raimundo; Efredo; Bernardo; Bosón; Arnulfo; Humberto; Arcado; Hugo; Guido; Duranio o Durando; Gerardo; Alano; Guigón; Jofre o Godofre; Yvo de Mont; Guillén de Busuel; Guillén de Monladún; y Giraldo. Sin embargo, ya desde el siglo XIII podemos hablar de una hispanización de la onomástica, pues los nombres franceses alternan cada vez más con los hispanos, como Martín Pérez, Gonzalo Pérez, Juan de

97 Francisco Javier GARCÍA TURZA, Documentación medieval del monasterio de Valvanera (siglos $X I V-X V)$, Logroño, 1990, doc. 158.

98 Este Diego de Garnica es el mismo que protagonizó un conflicto en el monasterio de Nájera ante la elección de Pablo Martínez de Uruñuela, como señalé más arriba. Por su parte, Fernando Díez de Zarratón tiene una trayectoria destacada en el cenobio najerense: entre 1460 y 1461 era mayordomo; y a partir de 1465 y hasta 1477, prior claustral y sacristán.

99 M. CANTERA, Regesta documental, no 181. 
Vargas o Pedro Sánchez ${ }^{100}$ y éstos son mucho más frecuentes desde el último cuarto del siglo XIV.

El nombre de Esteban puede responder tanto a la tradición franca como a la hispana; pero en el caso najerense se debe vincular a la influencia ultrapirenaica, y desde luego se confirma en el primero de los priores de este nombre en los años centrales del siglo XII, ya que correspondía a un momento de fuerte dependencia de Cluny y cuando todos los superiores tenían nombre francés. Más vinculados con la tradición franca están los nombres de Nicolás y Luis; sin embargo, el primero figura entre priores hispanos a principios del siglo XIII, lo que plantea dudas sobre su procedencia; por el contrario, Luis aparece en una etapa de priores francos, lo que parecería ratificar este origen.

En los años finales del siglo XII y los primeros del XIII, la larga relación de priores franceses se interrumpe con Jimeno o Semeno, nombre hispano; aunque también podría reflejar origen gascón ${ }^{101}$, las estrechas relaciones que mantuvo este prior con la familia Haro, importante bastión y apoyo del monasterio, parece ratificar su origen hispano.

También debemos hablar de nombres de tradición cristiana, comunes tanto en la onomástica francesa como en la hispana: Pedro, Juan, Esteban, Martín. En algunos casos, el segundo elemento del nombre ayuda a determinar su origen; así, Pedro Bellino sería franco, mientras que Pedro García y Pedro Martínez, hispanos. También podemos deducir el origen francés del prior Juan que, a principios del siglo XIII, aparecía acompañado de un sobrino de nombre Richart y de un criado llamado Raolín; sus nombres francos hacen pensar en que él también lo fuese ${ }^{102}$

Aunque en los otros oficios monásticos no es tan abrumadora la presencia de monjes franceses, tampoco es extraña, sobre todo en los primeros tiempos. Así, podemos señalar entre los priores claustrales a Roberto, Raimundo y Radulfo. Entre los sacristanes a Bernardo, Giraldo, Raimundo o Paris. Y a Rostanio, cillerero. Entre los limosneros hay más nombres francos: Giraldo, Juan de Belloico, Jofre y Guy; pero alternando con algunos tan hispanos como Iñigo, Fernando, Pedro Fernández y Juan Pérez.

De todas formas, todo nombre francés no tiene que indicar necesariamente origen ultrapirenaico, pues no podemos olvidar la presencia de importantes comunidades francas en algunas ciudades hispanas, como en el caso concreto de Nájera, situada en el Camino de Santiago. De todas formas, el elevado número de priores francos, y de forma continuada, así como la escasez de nombres hispanos en este cargo en los primeros tiempos, sugiere lo ya manifestado sobre el nombramiento de los priores

${ }^{100}$ En el caso del monasterio también cluniacense de San Pedro de Dueñas, Reglero de la Fuente (Dueñas, p. 248) constata una mayor presencia de monjes con nombre francés en el siglo XIV, debida a tres causas: nombramiento de los priores por el abad de Cluny, escasez de monjes en el priorato de Dueñas a principios de ese siglo (que haría necesario traer monjes de fuera) y, por el contrario, un número excesivo de monjes en los prioratos franceses, a los que no se podría alimentar con sus recursos. La situación no puede equipararse a la de Nájera, pues si es cierto que a principios del siglo XIV hay todavía priores de nombre francés, en la comunidad monástica predominan los nombres españoles.

101 C. REGLERO DE LA FUENTE, Cluny en España, p. 506.

102 Ibidem. 
por el abad de Cluny entre monjes de su propio monasterio, para asegurar el control sobre los prioratos alejados de la casa madre.

La fuerte presencia franca en el monasterio najerense contrasta especialmente con la onomástica de los monjes de otros cenobios riojanos, aunque las referencias son más bien escasas. Así, en Santa María de Valvanera desde principios del siglo XI los abades y monjes tienen nombres como Nuño o Munio, Aznar o Álvaro. En el caso de San Prudencio de Montelaturce se observa una evolución semejante a la de Santa María de Nájera, aunque a la inversa: los primeros monjes tienen nombres como Martín, Pedro o Iñigo; y a partir de su incorporación a la Orden del Císter, en 1181, figuran abades llamados Lamberto, Bernardo o Menaro ${ }^{103}$.

A partir del siglo XV es frecuente la utilización de un topónimo como apellido para designar a los miembros de la comunidad monástica, y así es posible conocer de qué localidad o región procedían. Por este medio podemos también observar la zona de influencia del monasterio najerense, pues si muchos de los topónimos pertenecen a la actual provincia de La Rioja, también son frecuentes los de Burgos, Álava y Navarra.

En un radio muy próximo a Nájera se encuentran las siguientes localidades: la propia ciudad de Nájera, Alesanco, Alesón, Arenzana de Arriba ${ }^{104}$, Azofra, Hormilla. Hormilleja, Huércanos, Mahave, Santa Coloma, Somalo, Torrecilla sobre Alesanco, Tricio y Uruñuela.

En un segundo círculo también próximo (entre 10 y $20 \mathrm{~km}$. a la redonda) tendríamos: Aguilar (debe tratarse de Aguilar de Bureba), Bañares, Baños (posiblemente Baños de Rioja), Berceo, Briones, Cirueña, Entrena, Matute, Nestares, Samaniego, San Millán (de la Cogolla), Santo Domingo de la Calzada, Tobía, Villalobar y Zarratón.

Muchos de estos lugares o villas están vinculados al monasterio de Santa María de Nájera de forma más o menos directa. Algunos de ellos pertenecían al señorío monástico desde fechas tempranas; es el caso de Arenzana de Arriba, Santa Coloma, Somalo, Cirueña, Entrena o Nestares, donados en diferentes momentos y por diversos otorgantes. En los demás casos la vinculación procedía de la cercanía o de la posesión de algún tipo de propiedad en el entorno de la villa, generalmente tierras y viñas.

La llegada de monjes a Santa María de Nájera también se produjo desde localidades alejadas, entre 20 y $50 \mathrm{~km}$. a la redonda. Entre las localidades burgalesas que entran en este ámbito están Belorado, Cameno, Fuentebureba y Redecilla (seguramente Redecilla del Camino). Las alavesas son Mijancas y Moreda. Y en Navarra se encuentran Cabredo y Torreviento (término de Viana); además hay que constatar la presencia de un monje llamado Pedro Martínez Navarro, apelativo que indica claramente su origen. También en este ámbito alejado de la ciudad de Nájera hay que incluir algunas localidades riojanas, como San Andrés y Villanueva (seguramente

${ }^{103}$ La antroponimia del monasterio de San Millán de la Cogolla ha sido analizada por José Ángel GARCÍA DE CORTÁZAR, "Antroponimia en Navarra y Rioja en los siglos X a XII”, en Estudios de Historia medieval de La Rioja, Logroño, 2009, pp. 187-204, aunque sin limitarse al caso concreto de los monjes y referida a los años 920-1160. En todo caso, se constata el hecho del predominio de nombres de origen navarro, como Sancho, García, Fortún o Blasco.

${ }^{104}$ Aunque en los documentos no se especifica habitualmente si se trata de Arenzana de Arriba o de Abajo, muy próximas entre sí, supongo que es la de Arriba, ya que esta villa pertenecía al dominio monástico najerense. 
Villanueva de Cameros). De todos estos lugares, Fuentebureba y Torreviento pertenecían al dominio monástico najerense.

Por último, hay una serie de localidades muy alejadas de Nájera, como las santanderinas de Cisero e Isla o la navarra de Rada; en los tres casos, la pertenencia al dominio monástico de estos lugares explica fácilmente la presencia de monjes procedentes de ellos. También se puede justificar en el caso de Burgos, ya que el cenobio poseía diversas propiedades, especialmente casas, en esa ciudad. Algo semejante ocurre en las localidades vascas de Bermeo, Guevara, Heredia, Vergara y Garnica (posiblemente Guernica), ya que el dominio económico tenía también sus ramificaciones en las Vascongadas. Sin ninguna relación con el dominio monástico está la ciudad de Soria, de la que había llegado un monje.

De las localidades antes señaladas se constata la procedencia de un número mayor de monjes de Arenzana (un total de 7 a lo largo del siglo XV), Matute (6 monjes, que vivieron en la segunda mitad del siglo XV), Santa Coloma (5, uno de ellos del siglo XIII y los demás del XV) y Cirueña (5, todos del XV). Este hecho refleja una fuerte influencia del monasterio en esas localidades, donde se concentraba además buena parte de su patrimonio.

Es curioso que sólo hay un monje del que consta su origen de la ciudad de Nájera; quizás se deba a la "competencia" de otros centros religiosos, especialmente San Millán de la Cogolla (con importantes propiedades en la ciudad), o la presencia de iglesias seculares que moverían a algunos najerenses hacia el clero secular. A ello habría que añadir los enfrentamientos que por diversos motivos económicos y jurisdiccionales se produjeron entre el monasterio y el concejo de Nájera, sobre todo en el siglo $\mathrm{XV}$; estos enfrentamientos no siempre se debían a litigios por propiedades del monasterio en la ciudad, sino que eran reflejo de conflictos señoriales entre el cenobio y alguna villa de su dominio, la cual recurría a las autoridades civiles de Nájera frente a su señor; quizás esos enfrentamientos provocaban un cierto rechazo en los najerenses hacia el monasterio.

Hay también un número relativamente alto de monjes procedentes de San Millán y de la cercana localidad de Berceo, lo que podría indicar un traslado de monjes desde el cenobio emilianense al najerense.

\section{NIVEL CULTURAL DE LOS MONJES DE SANTA MARÍA DE NÁJERA}

En los monasterios cluniacenses el trabajo intelectual tenía gran desarrollo, en sustitución del manual, pues la intensa dedicación a la liturgia y la solemnidad de las celebración de los oficios divinos, requería una elevada formación intelectual. Entre las dedicaciones del monje ocupaba un lugar privilegiado la copia de manuscritos y su ornamentación, al igual que otras artes que, como la orfebrería y la escultura, enriquecen las celebraciones litúrgicas ${ }^{105}$.

En las bibliotecas cluniacenses predominaban los libros religiosos: la Biblia, los Padres de la Iglesia (san Jerónimo, san Agustín, san Isidoro, san Ildefonso...), libros litúrgicos y de devoción. Pero a ellos se unían obras profanas: tratados gramaticales;

105 G. VALOUS, Le monachisme, I, pp. 312-315. 
obras de poetas clásicos (Virgilio, Ovidio, Lucano), de filósofos cristianos (como Boecio), tratados de medicina, etc. Estos libros servirían para conocer y perfeccionar la gramática y como un medio de actividad intelectual para comprender las Sagradas Escrituras ${ }^{106}$. Todo ello refleja la preocupación de Cluny por la formación intelectual de sus monjes, por lo que es raro encontrar casos de analfabetismo total entre los monjes profesos ${ }^{107}$.

Pocos son los datos que podemos obtener acerca del nivel cultural de los monjes najerenses, ya que son muy escasas y escuetas las noticias sobre el particular. La primera pista nos la daría la condición de bachiller que poseía alguno de los monjes del cenobio, y que sólo consta en cuatro ocasiones (quizás porque son las únicas): Domingo Fernández, bachiller en decretos (1407); Pedro Sánchez (1487); Martín Sánchez de Arenzana (1445-89); y Martín de Arenzana (1501-1506).

En segundo lugar habría que conocer la biblioteca del cenobio, lo que no resulta fácil dada la escasez de referencias documentales sobre el particular. La primera mención sobre la existencia de dicha biblioteca es del año 1193, cuando en el marco del pleito que enfrentó al cenobio con el obispo de Calahorra los monjes se quejaron contra dicho obispo porque sus criados furtive bibliotecam eiusdem ecclesie aportaverint ${ }^{108}$.

Más interesante es la carta del rey Alfonso X el Sabio que, el 27 de febrero de $1270^{109}$, reconocía haber recibido del cenobio najerense unos libros de letura antigua, prometiendo devolverlos en cuanto los hiciese copiar. Los libros prestados son dieciséis:

- "Las Editiones de Donato"; se trata de Aelius Donatus, autor de la Ars grammatica (minor et major), obra conocida y comentada en la Edad Media;

- "Statio de Tobas"; se trata de P. Papinus Statius, autor entre otras obras de La Thebaida.

- el "Catálogo de los Reyes Godos", posiblemente la Crónica Najerense ${ }^{110}$.

- "El Libro Juzgo de ellos", es decir el Fuero Juzgo, versión romanceada del Liber Iudiciorum de Recesvinto.

- Boecio, "de Consolación" (De consolatione Philosophiae).

- Un libro de justicia.

- "Prudencio", sin especificar qué obra.

- "Geórgicas" de Virgilio.

- Ovidio, "epístolas".

- "La historia de los Reyes de Isidro el menor", posiblemente el mal llamado Isidoro Pacense o Anónimo de Toledo y Córdoba, es decir, la Crónica Mozárabe de $754^{111}$.

- "Donato el Barbarisio";

- "Bucólicas" de Virgilio.

106 Ibidem, I, 313; según este autor, el mismo objetivo tenían las artes en general en la Orden de Cluny.

107 Ibidem, I, pp. 318-319.

108 M. CANTERA, Colección documental, doc. $\mathrm{n}^{\circ} 89$

109 M. CANTERA, Santa María la Real de Nájera, II, doc. 167. Estudiado en Margarita CANTERA MONTENEGRO, "Alfonso X y los cabildos y monasterios de La Rioja”, en Alfonso X el Sabio. Vida, obra, época, I, Madrid, 1989, p. 163; y Santa María la Real de Nájera, I, pp. 159-160. Agradezco al Dr. Martínez Pastor los datos aportados sobre muchos de estos autores.

110 Antonio BALLESTEROS BERETTA, Alfonso X el Sabio, Barcelona, 1984 (reedición), p. 498.

111 Iibidem, p. 498. 
- "Liber Illustrum virorum", que para Ballesteros no hay duda que se trata del libro de san Jerónimo así titulado, útil para la confección de la General Estoria ${ }^{112}$.

- "Preciano maior", probablemente Precianus, autor de las Institutiones grammaticae, libro también conocido y manejado en el medievo.

- "Boecio, sobre los diez predicamentos", inserto en su obra In categoriis Aristotelis, lib. IV.

- "El comento de Cicerón sobre el sueño de Scipión", fragmento que se halla al final de su De Republica.

Estos libros son agrupados por Ballesteros ${ }^{113}$ en tres tipos de obras: las de carácter histórico, como el Catálogo de los Reyes, la Historia de los Reyes, el Liber illustrum virorum y la obra de Stacio de Tebas. Dos de los libros son de Derecho, el Fuero Juzgo y el llamado libro de justicia; y otros son de puro solaz intelectual.

Cuando el 30 de mayo de 1334 el prior y convento de Santa María de Nájera hicieron inventario de los bienes que poseían ${ }^{114}$ se cita entre ellos: un misal; tres salterios, uno de los cuales tiene letras del oro; un libro en latín que habla de las elecciones de los príncipes primeramente; y, entre los bienes dejados por el sacristán Fernando Yáñez a su muerte, un libro deste, las tablas emplastadas y sobredoradas, et ymágenes de Nuestro Señor en ambas las tablas et sobredoradas, seguramente un libro de oración o litúrgico.

Nuevamente salen a la luz libros litúrgicos en 1379, cuando el 11 de noviembre los jueces designados para ello, el obispo de Burgos y un alcalde en la corte real, dictaron sentencia contra Garci Pérez de Camargo, acusado de haber robado bienes y joyas que le habían encomendado los monjes para protegerlos del pillaje de la guerra civil entre Pedro I y Enrique de Trastámara ${ }^{115}$. El prior reclamaba a dicho señor, entre otros muchos bienes, dos libros, un evangelario y un epistolario, ambos con cubiertas de plata; es posible que este epistolario sea el libro con tapas de marfil y plata alrededor que en este mismo proceso reclamaba el prior.

En el siglo XV, en 1407, hay otro documento significativo ${ }^{116}$ : el prior don Rodrigo donó 14 libros al convento y monjes del cenobio, estableciendo como condición que no los vendiesen ni empeñasen o enajenasen de alguna manera, aunque debían prestarlos al prior que, siendo letrado, quisiera estudiarlos; de todas formas, el convento conservaría siempre la propiedad de los libros.

Los libros donados son los siguientes:

- dos ejemplares de las Decretales recogidas por san Raimundo de Peñafort en 1234 (obra que también se conoce como Decretales extravagantes);

- de este mismo autor, una Suma Raimundina en pergamino, que podría tratarse de la Suma de Derecho Canónico;

- Decretales otros casos deste mesmo, que posiblemente se trata de la Suma de casos o Summa de casibus del mismo san Raimundo de Peñafort;

\footnotetext{
112 Ibidem, p. 499.

113 Ibidem, p. 498.

114 M. CANTERA, Santa María la Real de Nájera, II, doc. 274

115 M. CANTERA, Santa María la Real de Nájera, II, doc. 347

116 M. CANTERA, Regesta documental, nº 36.
} 
- el Liber Sextus o simplemente Sextus, que recoge las decretales pontificias promulgadas entre 1234 y 1298, y del que también hay dos ejemplares;

- una glosa de parte del Decreto, aunque no especifica de cuál se trata;

- un forma de libellos del que no podemos saber nada más, y que posiblemente formaría parte de los libros jurídicos;

- dos ejemplares de la Regla de san Benito, ambos en pergamino y descritos como de letra gruesa y de letra más delgada;

- unas epístolas de Pedro Blaseno, también conocido como Petrus Blasensis o Pedro de Blois, monje cisterciense de la segunda mitad del siglo XII;

- un Petrus de Vineis, que se trata de Piero della Vigne o Pedro de las Viñas, poeta de la primera mitad del siglo XIII (c. 1190-1249), canciller y secretario del emperador alemán Federico II;

- un libro de rectoría, del que no es posible especificar nada más; cabría pensar que sea un libro de retórica;

- un Juan Monje; a pesar de la imprecisión, pienso que podría tratarse de Juan Casiano, monje, Padre de la Iglesia y escritor ascético, autor del que se conservan dos obras dirigidas a sendas comunidades monásticas: las Instituciones, en las que exponía las obligaciones de los monjes y examinaba los vicios contra los que debían estar prevenidos; y las Collationes en las que, en forma de diálogo con monjes de la antigüedad, trataba diversos aspectos de la vida monástica. Desde luego es autor que figuraba frecuentemente en las bibliotecas monásticas;

- Los Tajos de Raimundo de Salgis, o de Salguis o de Salgas, canonista parisiense del siglo XIV, autor del Ars inveniendi themata ex Decreto. Podría tratarse de una confusión en la transcripción de la palabra tajos por casos.

Como soporte de la escritura destaca el pergamino, ya que 11 de los libros son de este material y sólo 3 de papel.

\section{CONCLUSIONES}

El cenobio najerense es un monasterio cluniacense en el pleno sentido de la palabra, con total vinculación jurídica a la abadía francesa y organización interna igual a la existente en los demás centros de la Orden. Y ello se refleja con claridad en este estudio de la comunidad monástica durante el período medieval, al final del cual precisamente se rompieron los lazos de dependencia respecto a la Orden de Cluny.

También se reflejan a lo largo de estas páginas, aunque sea de forma tangencial, algunos de los fenómenos significativos de su historia: la progresiva hispanización de sus monjes, especialmente de sus priores y otros cargos monásticos. La evolución del monasterio desde los momentos de esplendor de los primeros años a la crisis del siglo XIV, así como los síntomas de recuperación de la misma, reflejado todo ello en el número de monjes que vivía en el cenobio. Y algunos datos sobre el nivel intelectual de sus habitantes que pueden desprenderse tanto de los títulos académicos que obtuvieron varios de los monjes como de la constatación de ciertos libros que contenía su biblioteca. 


\section{OFICIALES DE SANTA MARÍA DE NÁJERA (S. XII-XV)}

Las fechas, por lo general, señalan el primer y último año en que esa persona aparece en la documentación ejerciendo ese oficio. Entre corchetes se recogen casos dudosos.

\section{Priores MaYores}

Marcelino, 1081-87

Raimundo, 1106-10

Efredo, 1110

Pedro Bellino, 1112-33

Esteban, 1135-43

Bernardo, 1143

Juan, 1145

Bosón, 1149

Arnulfo, 1151-53

Raimundo, 1155-69

Humberto, 1170-71

Arcado, 1174

Hugo, 1175

Guido, 1179-83

[Haimón, 1179]

Duranio o Durando, 1190-94

Jimeno, 1197-1201

Gerardo, 1203-05

[Jimeno, 1207]

Alano, 1214

Guigón, 1216-20

Jimeno, 1220

Juan, 1222-30

Nicolás, 1235-39

Martín Pérez, 1245

Guido, 1249-50
Gonzalo Pérez, 1258-61

Esteban, 1266-72

Jofre o Godofre, 1272

Juan de Vargas, 1272-79

Pedro Sánchez, 1286-95

Yvo de Mont, 1298

Guillén de Busuel, 1312

Luis, 1314

Guillén de Monladún, 1316

Luis, 1318-36

Enrique, 1339-49

Pedro, 1355-56

Giraldo, 1361

Guido, 1362-75

Pedro García Diáñez, 1377-80

Guido, 1380-82

[Enrique, 1382]

Juan de Redecilla, 1382-89

Fernando, 1392-96

Rodrigo López, 1399-1419

Guido, 1420

Pedro Martínez de Santa Coloma, 1423-53

[Pablo 1442]

Gonzalo de Cabredo, 1456-86

Pablo Martínez de Uruñuela [luego abad], 1486-91

\section{$\underline{\text { AbadeS }}$}

Pablo Martínez de Uruñuela [antes prior mayor], 1492-1507

Fernando Marín de Huércanos, abad comendatario, 1501-11 


\section{Priores Claustrales}

Roberto, 1123

Raimundo, 1143

Domingo, 1175

Radulfo, 1183

Pedro, 1201

Juan, 1214

Paris, 1222

Roberto, 1224

Paris, 1225-26

Guillermo, 1239

Pedro de Bañares, 1258

Sancho Garcez, 1273

Pedro Sánchez, 1279

Martín Fernández, 1290

Martín Sánchez, 1320
Pedro, 1344

Juan Pérez de Pradela, 1348-49

Pedro Martínez, 1363-69

Alfonso González, 1369

Pedro, 1381

Gonzalo Pérez, 1385-97

Pedro, 1389

Alfonso Pérez, 1399

Pedro Martínez de Santa Coloma, 1404-25

Pedro García Manso de Nestares, 1431-43

Martín Sánchez de Arenzana, 1457-72

Pedro Fernández de Soria, 1460

Fernando Díez [o Díaz] de Zarratón, 1465-72

Pablo Martínez de Uruñuela, 1484

Pedro Martínez de Burgos, 1489-1502

\section{Vicedominis}

Martín Pérez, 1239

Jimeno, 1239

\section{Socii prior claustralis}

Pedro, 1220-22

Fernando, 1239

\section{Camareros o tesoreros}

Jimeno (señor del vestuario), 1239

Pascual (señor del vestuario), 1258

Gómez (señor del vestuario), 1273

Fernando Martínez, 1396

Pablo Martínez de Uruñuela (tesorero), 1465

Fernando Martínez de Azofra (tesorero), 1488-89 


\section{Sacristanes}

Bernardo, 1123

García Pérez, 1304-11

Juan, 1123-43

Pedro Yáñez, 1320-23

Blasco Pérez, 1145

Per Sánchez, 1326

Pedro, 1175

Giraldo, 1183

Pedro Yáñez, 1334-42

Juan Pérez, 1344

Pedro, 1201

Pedro, 1365

Juan, sacrista minor, 1201

Domingo Pérez, 1369

Raimundo, 1214

Alfonso González, 1385-86

Pedro, 1220

Paris, 1222

Roberto, 1223-24

Martín Yáñez, 1225-26

Martín Pérez, 1239

Juan López, 1258-59

Jaco, 1273-90

Martín García, 1294

Fernando Martínez, 1386-88

Alfonso Pérez, 1392-1410

Pedro Fernández, 1412

Pedro García Manso de Nestares, 1422-32

Martín Sánchez de Arenzana, 1457-58

Pedro Fernández de Soria, 1460

Fernando Díez [o Díaz] de Zarratón, 1465-77

Francisco Martínez Boy, 1484

\section{Subprior}

Diego Martínez de Somalo, 1493-1507

\section{Limosneros}

\author{
Andrés, 1143 \\ Pedro, 1175 \\ Giraldo, 1183 \\ Juan de Belloioco, 1201 \\ Martín, 1214 \\ Iñigo, 1220 \\ Fernando, 1224 \\ Pedro, 1239 \\ Jofre, 1258 \\ Pedro Fernández, 1273 \\ Juan Pérez, 1334 \\ Guy, 1348 \\ Gonzalo Pérez, 1365
}

\author{
Pedro, 1369-81 \\ Gonzalo Pérez, 1382 \\ Juan Martínez, 1385-99 \\ Pedro, 1389 \\ Juan Martínez, 1401-23, 1432 \\ Juan García, 1418 \\ Gonzalo Pérez, 1420 \\ Juan Martínez de San Millán, 1420-36 \\ Martín Sánchez, 1442 \\ Sancho Sánchez de Samaniego, 1460 \\ Pedro Martínez de Tobía, 1461-67 \\ Pedro Martínez de Burgos, 1476-84
}




\section{Enfermeros}

Lope, 1220-26

Pedro, 1245

Pedro de Cañas, 1258

Martín de Torrecilla, 1273

Martín García, 1290

Pascual Pérez, 1365

Juan Martínez de Hormilleja, 1381

Fernando Martínez, 1385-86

Alfonso Pérez, 1386-89

Sancho Martínez, 1396-99
Pedro Martínez de Santa Coloma, 1401-06

Martín Sánchez de Arenzana, 1427-35

Pedro Sánchez de Cárdenas, antes de junio 1448

Pedro García de la Puente, 1448

Sancho Fernández, 1457

Sancho Sánchez de Villanueva, 1459-60

Mateo Pérez de Arenzana, 1461-65

Pablo Martínez de Uruñuela, 1468-84

Pedro Manso, 1488-89

\section{$\underline{\text { MAYORDOMOS }}$}

[Guillermo, 1201]

Jacobo, 1220

Martín Pérez, 1222

Lope, 1224

Martín Yáñez, 1225

Martín Pérez, 1369

Fernando Martínez, 1381

Juan López, 1396

Juan García, 1404

Juan Martínez de San Millán, 1405-36

Fernando Martínez de Alesón, 1425-35

Pedro Martínez de Tobía, 1452-58
Fernando Sánchez de Pavía, 1460

Femando Díez [o Díaz] de Cerratóno Zarratón, 1460-61

Pedro Sánchez de Bañares, 1465

Juan Martínez de Bañares, 1467

Pedro Martínez de Burgos, 1468-71

Martín Fernández de Moreda, 1476-77

Pablo Martínez de Uruñuela, 1471

Diego Martínez de Somalo, 1477-87

Juan Sánchez de Baños, 1488-1500

Juan de Baños, 1495-1503

Martín de Arenzana, 1505-06

Juan de Nestares, 1507

\section{Cillereros}

Rostanio, 1081

Pelayo, 1143

$\mathrm{Al}$ [cellerarius coquine] 1175

García, 1220

Sancho, 1220-24

Fernando [sennor de la cozina], 1220-22

García [sennor de la cozina], 1224

Juan López [sennor de la cozina], 1239

Pedro de Cañas [sennor de la cozina], 1258
Domingo Yáñez [pitancero], 1290

Pedro Fernández de Heredia, 1407-09, 1431, 1436

Juan García, 1411-12

Juan Alfonso de Berceo, 1425

García Pérez de Santa Coloma, 1457-68

Pablo Martínez de Uruñuela, 1460

Martín Fernández de Moreda, 1477

Pedro Fernández de San Millán, 1488

Francisco [despensero], 1508

\section{Mayordomo del abad}

Juan de Mijancas, 1496 


\section{Refitoleros}

Pedro, 1175

Toribio González, 1388

\section{Obrero o mayordomo de la obra nueva}

Sancho Sánchez de Villanueva, 1459, 1467-79

Juan Martínez de Cirueña, 1484-89

\section{Sochantre, armarius o cantor}

S. [armarius], 1223

Fernando [armarius], 1239

Juan Pérez, 1348

Fernando Sánchez, 1356

Alfonso Pérez de Fuentebureba, 1385-86

Fernando Martínez, 1397-99

Pedro Fernández, 1404-06

Diego Martínez de Alesón, 1422
Juan Patea, 1425

Juan Sánchez de Briones, 1431-35

Fernando Sánchez de la Cernilla, 1457

Pablo Martínez de Uruñuela, 1457

Fernando Martínez de Azofra, 1460-68

Juan Sánchez de Matute, 1468-76

Juan González de Tobía, 1479

Martín Sánchez de Arenzana, 1488-89

\section{Socantor}

Fernando Martínez de Azofra, 1460, 1467

\section{Claveros}

Guillermo, 1183

Lope Navarro de Torreviento, 1201

Nicolás, 1290

Juan Pérez, 1322

Pedro, 1392

Diego Fernández, 1407

Sancho Sánchez de Villanueva [clavero del prior], 1449

\section{Portero}

Juan Fernández, 1411 


\section{PROCEDENCIA GEOGRÁFICA DE LOS MONJES}

Muy cercanos a Nájera (menos de $10 \mathrm{~km}$. a la redonda)

- $\quad$ Alesanco - Diego Martínez de Alesanco 1421, 1422

- $\quad$ Alesón - Fernando Martínez de Alesón 1385

- Arenzana [de Arriba] -

Diego Ramírez de Arenzana 1493

Martín de Arenzana 1435 (infante)

Martín de Arenzana 1435

Martín de Arenzana 1501-06

Martín Sánchez de Arenzana 1427-35 ó 1446

Martín Sánchez de Arenzana 1446 ó 1457-89

Mateo Pérez de Arenzana 1461-65

- $\quad$ Azofra - Fernando Martínez de Azofra 1465-96

- $\quad$ Cañas - Pedro de Cañas, 1258

- $\quad$ Hormilla - Juan Martínez de Hormilla 1385-89

- $\quad$ Hormilleja - Juan Martínez de Hormilleja 1381

- Huércanos - Fernando Marín de Huércanos 1493-1511 (abad comendatario)

- Mahave - Pedro de Mahave 1435

- $\quad$ Nájera - Fernando de Nájera 1507

- Santa Coloma -

Diego Martínez de Santa Coloma 1484

García Pérez de Santa Coloma1457-68

Gonzalo Díez de Santa Coloma 1470

Pedro Martínez de Santa Coloma 1404-53

Johan de Santa Coloma 1258

- $\quad$ Somalo - Diego de Somalo = Diego Martínez de Somalo 1476-1507

- Torrecilla (sobre Alesanco) - Martín de Torrecilla 1273

- $\quad$ Tricio - Juan de Tricio 1496-1507

- Uruñuela -

Juan de Uruñuela 1496-1500

Pablo Martínez de Uruñuela 1457-1507

$\underline{2^{\circ} \text { círculo (entre } 10-20 \mathrm{~km} \text {. a la redonda) }}$

- $\quad$ Aguilar (seguramente A. de Bureba) - Fernán Pérez de Aguilar 1431

- Bañares -

Juan Martínez de Bañares 1465-67

Pedro Bañares 1258

Pedro Sánchez de Bañares 1465

- $\quad$ Baños (seguramente B. de Rioja) -

Diego de Baños 1500

Francisco de Baños 1497

Juan Sánchez de Baños 1479-1507

Pedro Martínez de Baños 1484

Pedro Pardo de Baños 1498-99

- $\quad$ Berceo - Juan Alfonso de Berceo 1425

- $\quad$ Briones - Juan Sánchez de Briones 1431-35 


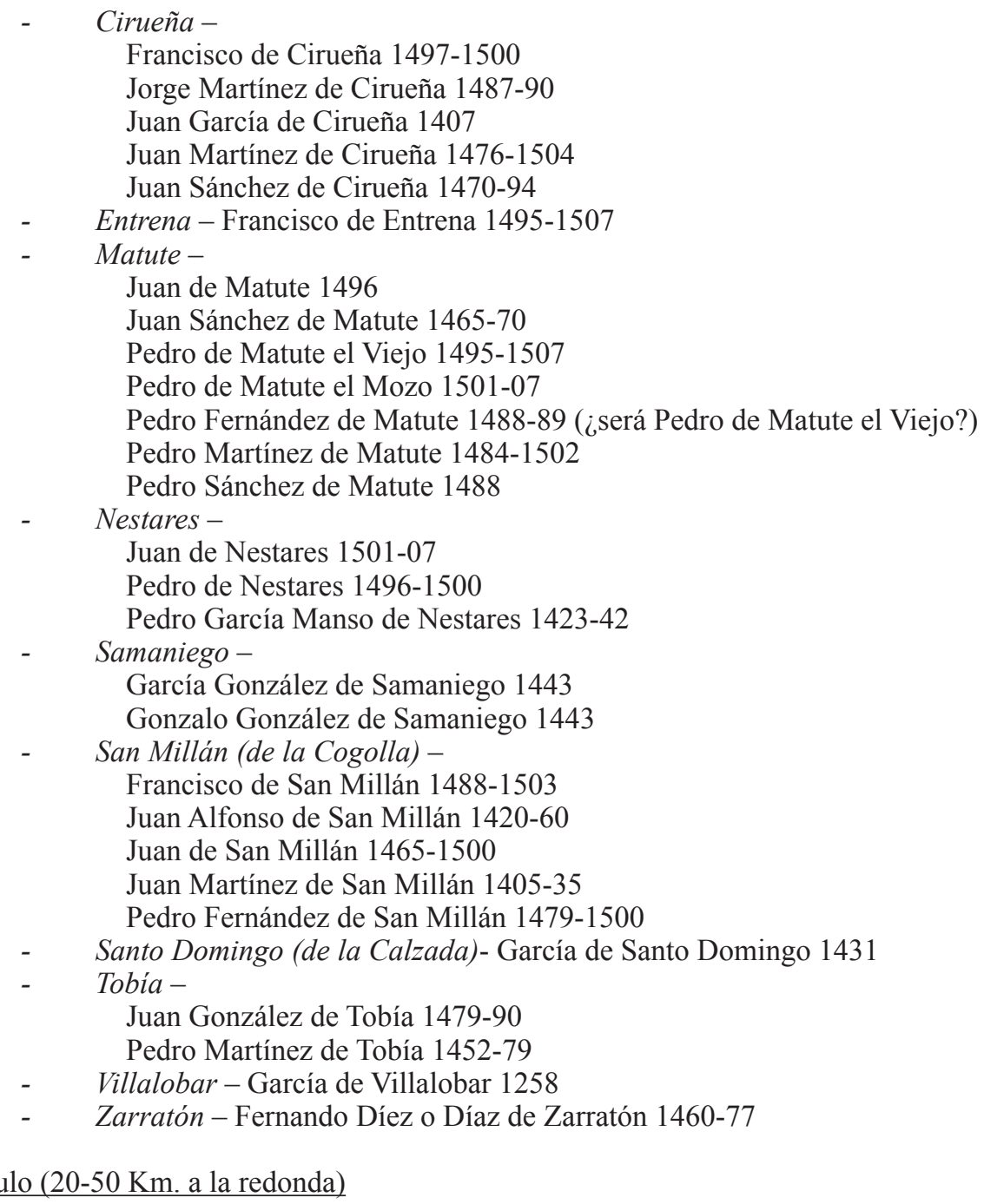

$\underline{3}^{\text {er }}$ círculo $(20-50 \mathrm{Km}$. a la redonda $)$

\section{hacia el oeste (prov. Burgos)}

- $\quad$ Belorado - Pedro Pérez de Belorado 1410-19

- $\quad$ Cameno - Juan Martínez de Cameno 1431-35

- $\quad$ Fuentebureba - Alfonso Pérez de Fuentebureba 1385-86

- $\quad$ Redecilla [seguramente Redecilla del Campo] - Juan de Redecilla 1387 hacia el oeste y norte (provs. Álava y Navarra)

- $\quad$ Cabredo - Pedro de Cabredo 1496-1501 (Navarra)

- $\quad$ Mijancas - Juan de Mijancas 1494-99 (Álava)

- $\quad$ Moreda - Martín Fernández de Moreda 1477 (Álava)

- $\quad$ Torreviento (Viana) - Lope Navarro de Torreviento 1201 (Navarra)

- $\quad$ Pedro Martínez Navarro 1484 


\section{hacia el sur (prov. Logroño)}

- $\quad$ San Andrés - Francisco de San Andrés 1507

- Villanueva (seguramente V. de Cameros) - Sancho Sánchez de V. 1449-84

$\underline{4^{\circ} \text { círculo (más de } 50 \mathrm{~km} . \text { a la redonda) }}$

\section{Vascongadas}

- $\quad$ Bermeo - Juan González de Bermeo 1438

- Garnica (¿será Guernica?) - Diego de Garnica (o D. Martínez de G., D. Sánchez de G.) 1468-91

- $\quad$ Guevara - Francisco de Guevara 1501

- $\quad$ Heredia - Pedro Fernández de Heredia 1407-36

- Vergara-

Gonzalo de Cabredo, alias de Vergara 1457-86

Próspero de Vergara 1484-1507

\section{Burgos}

- Burgos - Pedro Martínez de Burgos 1461-1502

\section{SANTANDER}

- $\quad$ Cisero - Juan Gutiérrez de Cisero 1431-35

- $\quad$ Isla - Francisco de Isla 1495-1507

NAVARRA

- Rada-

Juan de Rada 1496-1507

Pedro Rada 1499

\section{Otros}

Soria - Pedro Fernández de Soria 1423-60 